\title{
Structural Transformation and the Oil Price ${ }^{1}$
}

\author{
Radosław (Radek) Stefański \\ University of Minnesota
}

First Version: June 1, 2008

This Version: June 23, 2009

\footnotetext{
1 I would like to thank Timothy Kehoe and Fabrizio Perri for their continued guidance and support during this project. I would also like to thank Cristina Arellano, Patricia Justino, Joe Kaboski, Narayana Kocherlakota and Miguel Ricaurte as well as members of the Minnesota International Trade and Development Workshop for helpful comments and suggestions. I thank Hossein Samiei and Kevin Cheng for initial discussion. I have also benefited from comments of seminar participants at the Summer Meeting of the Econometric Society (Pittsburgh), Minneapolis Federal Reserve Bank Seminar Series (Minneapolis), La Pietra-Mondragone Workshop (Florence), Washington University in St. Louis Graduate Student Conference (St. Louis), International Economic Meetings (Warsaw) and the Workshop for Young Economists (Guanajuato). All errors are my own. Contact: rstefans@econ.umn.edu
} 
What part of the rising trend in the oil price is driven by structural transformation in China and India? Will continued structural transformation in these countries result in a permanently higher oil price? I identify an inverted-U shaped relationship in the data between aggregate oil intensity and the extent of structural transformation - countries in the middle stages of transition spend the highest fraction of their income on oil. A decomposition of aggregate oil intensity shows that only in the middle stages of transition are an economy's largest sectors also its most oil intensive ones. I construct a multi-sector, multi-country, general equilibrium growth model that accounts for these facts and use it to measure the impact of changing sectoral composition in China and India on world oil demand and hence the oil price in the OECD. Structural transformation in China and India accounts for up to a quarter of the oil price increase in the OECD between 1970 and 2007. However, continued structural transformation in China and India results in falling oil intensity and a drop in the oil price. Using a standard growth model misses this non-linearity and can give misleading implications about the long-term oil price. To understand the impact of growth on the oil price, it is necessary to take a more disaggregated view than is standard in macroeconomics. 


\section{Structural Transformation and the Oil Price}

\section{$1.1 \quad$ Introduction}

A structural transformation is a shift in the composition of an economy, away from agriculture towards industry and services, that accompanies growth ${ }^{2}$. Between 1970 and 2007 as the real oil price in the United States and other countries rose by over $500 \%$ BP (2008), world employment share in agriculture fell from 56\% in 1970 to just under $36 \%$ in the mid-2000's ILO (2003). This transformation was driven - to a large extent by declines in agricultural employment in the world's two largest countries, China and India. Employment in the agricultural sector in China and India declined from nearly $80 \%$ of the labor force in 1970 to just under $50 \%$ by the mid-2000's 3 . What part of the increase in the oil price in rich countries can structural transformation in very large, poorer countries account for? In particular, what part of the oil price increase is driven by structural transformation in China and India and are the effects on prices necessarily permanent?

Why does structural transformation influence the oil price? I document how the demand for oil changes with structural transformation - as the structure of an economy

\footnotetext{
2 Both in terms of employment shares and value-added per sector shares.

3 A back-of-the-envelope calculation that assumes that China and India's share in the world's total labor force is $1 / 3$, reveals that structural transformation in China and India accounted for just over $40 \%$ of the world's decline in agriculture employment over this period.
} 
shifts away from agriculture towards industry and services, economies first spend a rising and then a falling share of their income on oil. Intuitively, countries at different phases of structural transformation use different intensities of oil: industrialization, urbanization and the construction of new infrastructure involves the use of large quantities of raw materials. China and India have reached the most commodity-intensive stage of their development and are the last large countries to enter this phase of transformation. Due to their size, they can potentially exert a very large impact on the world oil demand and hence on the world oil price. As China and India industrialize, they consume a higher share of world oil supply, leaving a smaller share for other countries resulting in upward oil price pressure in the rest of the world. By the same argument, as structural transformation in China and India comes to a close in the future, their demand for oil should ease and the upward pressure on oil prices should drop.

I develop a multi-sector, multi-country, general equilibrium growth model similar to Echevarria (1997), Duarte and Restuccia (2007) and Rogerson (2007) - but with international trade and oil as an intermediate input - that explains the existence of the inverted-U oil intensity curve through changing sectoral oil intensities over the transition of an economy. I use the model to measure the impact of structural transformation in China and India on the oil price in the OECD. I find that structural transformation in China and India accounts for up $24 \%$ of the increase in oil prices in the OECD. Furthermore, I find that the upward price pressure caused by structural transformation is not necessarily permanent.

Since the model is designed to to capture the effects of structural transformation on the oil price, it focuses on the evolution of oil demand - and abstracts away from oil supply dynamics, uncertainty, speculation and imperfect competition. In particular, oil output is modeled as inelastically increasing. In the model, structural transformation is driven by two channels: income effects arising from non-homothetic preferences as in Kongsamut et al. (2001) and substitution effects due to unbalanced productivity growth across sectors as in Ngai and Pissarides (2007). The oil price result is driven by a further two channels: a supply side effect caused by inelastically growing oil supply and a demand side effect that arises from changing sector-specific oil intensities. 


\subsection{Facts}

In this section I document two sets of facts. The first set demonstrate that: 1) there has been a rising trend in oil prices since the 1970's; 2) China and India have undergone a large structural transformation and that 3) China and India's share in world oil consumption has risen, whilst that of more advanced countries has fallen. The second set of facts is associated with structural transformations in general: 4) the existence of an inverted-U aggregate oil intensity curve along a structural transformation $\left.4^{4} ; 5\right)$ the changing size of sectors along a structural transformation and 6) changing sector specific oil intensities. I use facts 5) and 6) to motivate the existence of fact 4) - the inverted- $\mathrm{U}$ aggregate oil intensity. I conclude the section by motivating a seventh fact: 7) the inelastic nature of oil supply.

\subsubsection{The Oil Price}

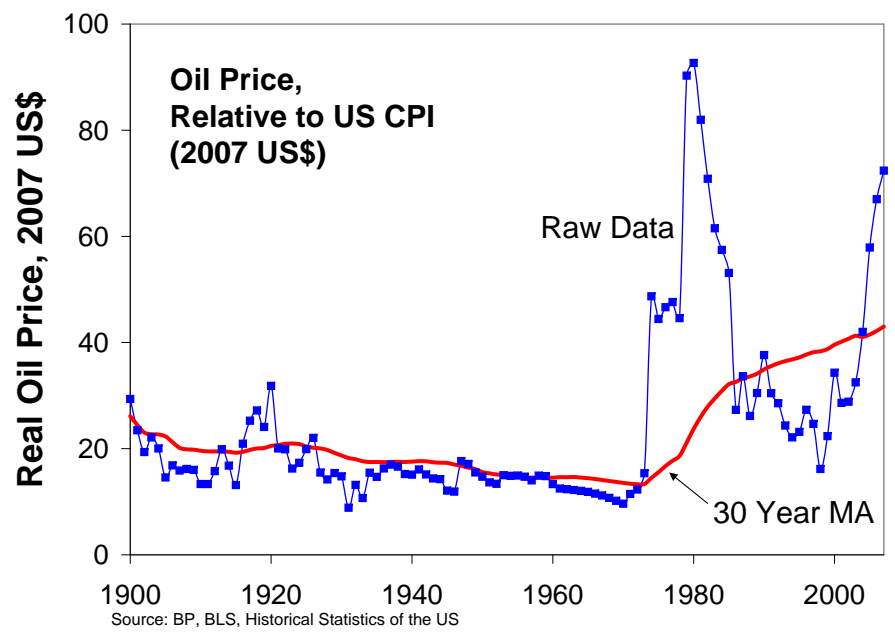

Figure 1.1: Real Oil Price and its Trend (Relative to the US CPI).

The curve labeled "Raw Data" in Figure 1.1, shows the 1900-2007 average annual oil price in 2007 US dollars $\mathrm{BP}$ (2008). The oil price shocks of the 1970's and 80's

\footnotetext{
4 As far as I am aware, this paper is the first to document this fact for oil.

5 In this section all dollar amounts refer to 2007 USD. Quantities are deflated by the US Consumer Price Index. The CPI data for 1900-1913 data comes from the Historical Statistics of the United States (http://hsus.cambridge.org), whilst the 1913-2007 data comes from the BLS.
} 
as well as recently rising oil prices are clearly visible in the figure. The focus of this paper however, are not the sharp shocks in the raw data, but rather the oil price trend. The average oil price for the 38 year period, 1970-2007, was approximately 41 USD. The average oil price in the 38 years preceding that (1932-1969), was 14 USD. This represents an almost 200\% increase in oil prices. Taking a 30 year moving average of the raw data emphasizes this upward trend. From 1970 to 2007, the real oil price (as measured by the 30 year MA) has also roughly tripled - from 14 to 43 dollars. In this paper, "the oil price" will refer to this 30 year MA. Finally, notice that there is a significant change in the trend of the oil price after the 1970's: the oil price, which had been falling for nearly a century, began to rise sharply. A part of this is due to the oil shocks of the 1970's and 1980's, however in this paper I argue that a significant portion of this changing trend stems from structural transformation in China and India.

\subsubsection{China and India's Structural Transformation}

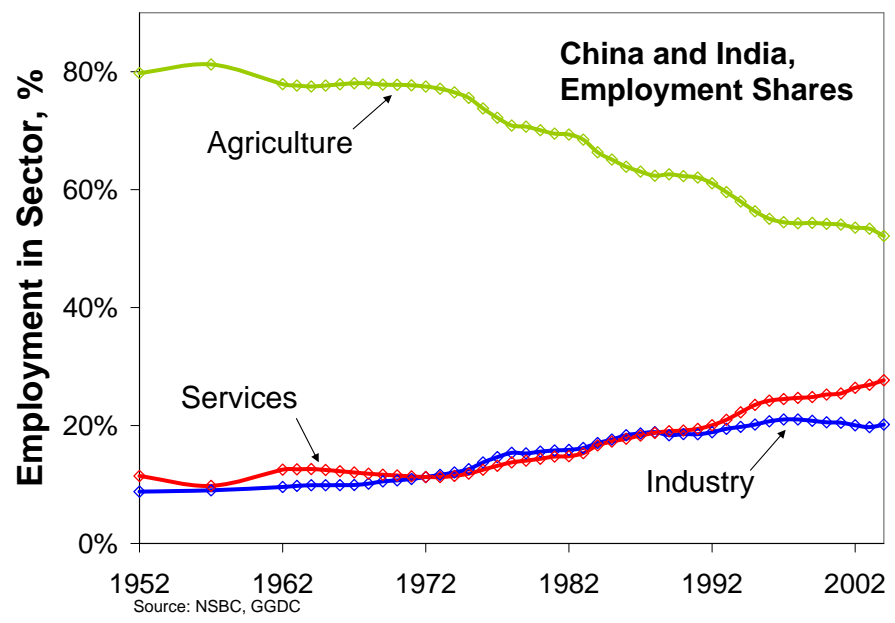

Figure 1.2: Structural Transformation in China and India: Employment Shares by Sector in China and India (1952-2004).

Figure 1.2 shows how China and India's employment share in agriculture has fallen from nearly $80 \%$ in 1970 to approximately $50 \%$ by 2004 . At the same time, the share 
of employment in industry and services has risen from approximately 10\%, to approximately $20 \%$ in industry and $30 \%$ in services ${ }^{6}$. In absolute terms, this is one of the largest inter-sectoral movement of labor in history $]^{7}$.

\subsubsection{World Oil Shares}

China and India's structural transformations coincided with a rise in their share in world oil consumption. Figure 1.3 shows how China and India's share in world oil consumption rose by approximately $13 \%$ between 1970-2007. Meanwhile, the share of the EU-25, the US and Japan in world oil consumption fell by approximately $21 \% 8$.

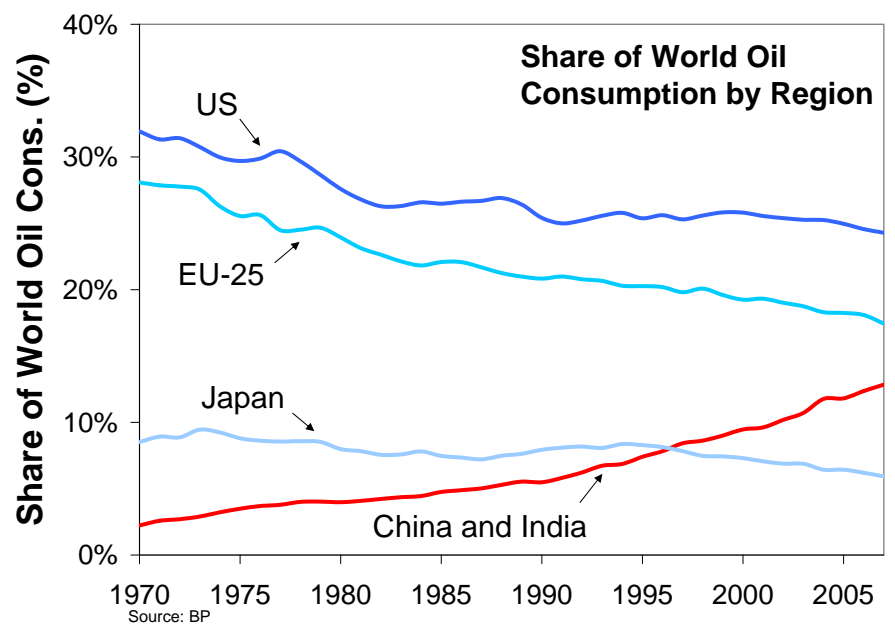

Figure 1.3: World oil shares in China, India and the world's largest oil consumers (1970-2007).

In what follows, I index the progress of a country along a structural transformation by its share of employment in agriculture9 . Countries with high shares of employment in GDP are relatively structurally undeveloped whereas countries that have lower agriculture shares are more structurally developed.

6 The sources for this data are: Timmer and de Vries (2007), NBSC (2006).

7 Notice, that in this paper I choose to concentrate on movement of labor across sectors rather than changing shares of GDP.

8 This data comes from $\mathrm{BP}(2008)$.

9 The index itself is fairly unimportant. Alternatively, I could consider a country's share of GDP arising from agriculture or its income per capita - any yardstick that is positively correlated with a structural transformation is appropriate and was checked to give similar results. 


\subsubsection{Aggregate Oil Intensity}

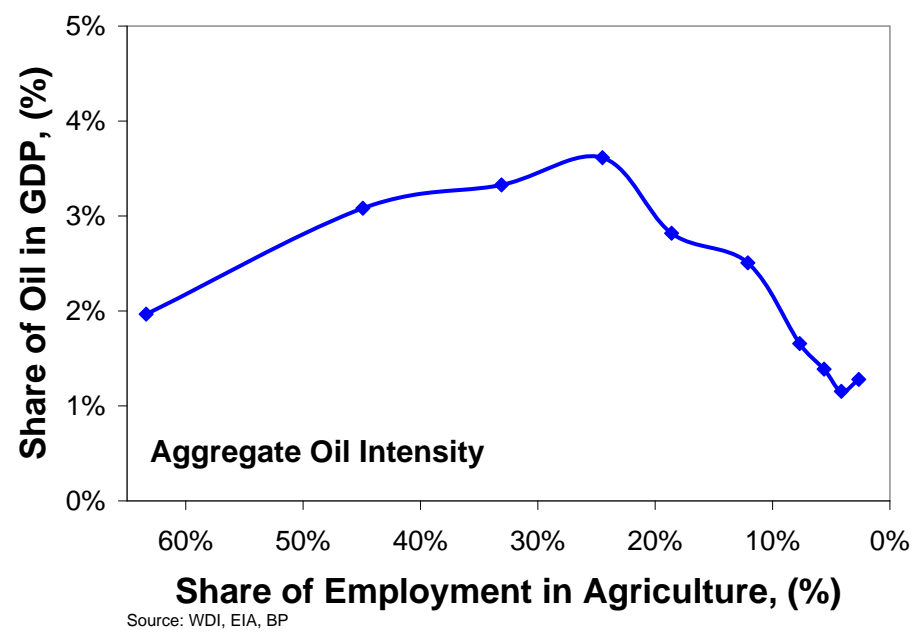

Figure 1.4: Share of oil in GDP vs. share of employment in agriculture for a panel of the world's 100 largest countries by population (in 2000) for the years, 1980-2005. Line indicates the decile averages of the data.

The share of GDP spent on oil (or the aggregate oil intensity) varies with the progress of a structural transformation. Countries at the beginning and end of a structural transformation spend the lowest share of their income on oil, whilst countries in the "middle" of a structural transformation spend the highest share. This is shown in Figure 1.4, which plots decile averages of aggregate oil intensity versus the share of employment in agriculture for a panel of the world's largest 100 countries (for the years 1980-2005) $\sqrt{10}$. Oil consumption come from the EIA and GDP shares data comes from WDI (2007), whilst price data come from BP (2008) . The pooled data is sorted according to employment share in agriculture, divided into ten groups, and the average employment share in agriculture and the average oil intensity of each group is shown in the above graph. The inverted-U shape of aggregate oil intensity is clearly visible. To test the robustness of this result, I run a quadratic regressions (both OLS and LAV) with time dummies on the panel data - the results are shown in Table 1.1 .

\footnotetext{
10 This is done in order to avoid including many small island economies. The largest 100 countries are chosen according to their population in the year 2000.

11 Oil prices used to calculate the above shares, are smoothed using a 30 year moving average to remove sharp spikes in prices. For more details on the construction of the data see Appendix 1.9.1
} 
Agg. Oil Int. vs. Share of Agr. in Emp and Time Dummies

\begin{tabular}{lcc}
\hline & $(1)$ & $(2)$ \\
COEFFICIENT & Aggregate Oil Int. (OLS) & Aggregate Oil Int. (LAV) \\
\hline agrShare & $0.130^{* * *}$ & $0.091^{* * *}$ \\
& $(0.0063)$ & $(0.00430)$ \\
agrShareSq & $-0.168^{* * *}$ & $-0.110^{* * *}$ \\
& $(0.0091)$ & $(0.00624)$ \\
$R^{2}$ & 0.330 & 0.229 \\
Pseudo $R^{2}$ & & \\
& \multicolumn{3}{c}{ Standard errors in parentheses } \\
& $* * * \mathrm{p}<0.01,{ }^{* *} \mathrm{p}<0.05,{ }^{*} \mathrm{p}<0.1$
\end{tabular}

Table 1.1: Regression of aggregate oil intensity versus share of employment in agriculture (and time dummies) for a panel of 100 countries over the period 1980-2005. (Coefficients for time dummies and constant term not shown.)

In both regressions all coefficients are highly significant. Furthermore, the structural development of a country (as measured by the share of employment in agriculture) can explain $33 \%$ of the variation in aggregate oil intensity across countries and time. I also run several non-parametric regressions - all of which confirm the existence of an inverted- $\mathrm{U}$ aggregate oil curve in the panel data.

I motivate the existence of the inverted- $U$ by a particular decomposition of aggregate oil intensity. Intuitively, the oil intensity of an entire economy, must result from the oil intensities of individual sectors, weighed by their size. In particular, suppose $Y$ is the value added and $O$ the total oil consumption of a three sector economy composed of agriculture (A), industry (I) and services (S). Let $Y_{i}$ denote the value added and $O_{i}$ the oil consumption of each of the three sectors, $i=A, I, S$, so that $O=\sum_{i} O_{i}$ and $Y=\sum_{i} Y_{i}$. Finally, let $p_{O}$ be the price of oil. The oil intensity of an entire economy $\left(N \equiv \frac{p_{O} O}{Y}\right)$, is simply the sum of oil intensities of each sector $\left(n \equiv \frac{p_{O} O_{i}}{Y_{i}}\right)$, weighted by its size $\left(s_{i}=\frac{Y_{i}}{Y}\right)$ :

$$
N \equiv \frac{p_{O} O}{Y}=\sum_{i}\left(\frac{p_{O} O_{i}}{Y_{i}} \frac{Y_{i}}{Y}\right)=\sum_{i} n_{i} s_{i} .
$$

Aggregate oil intensity of an economy depends on both the sector specific oil intensity and the size distribution of individual sectors at any point along a structural 
transformation. To understand how aggregate oil intensity changes, it is necessary to understand how the size of sectors and the sector specific oil intensities change over a structural transformation.

\subsubsection{Changing Sector Size}

The process of structural transformation has been widely documented in the literature. It is characterized by shares employment and value added that are falling in agriculture, rising in services, and initially rising and later falling in industry 12 . Figure 1.5 shows this typical pattern for employment shares in the United States over the 1860-2004 period.

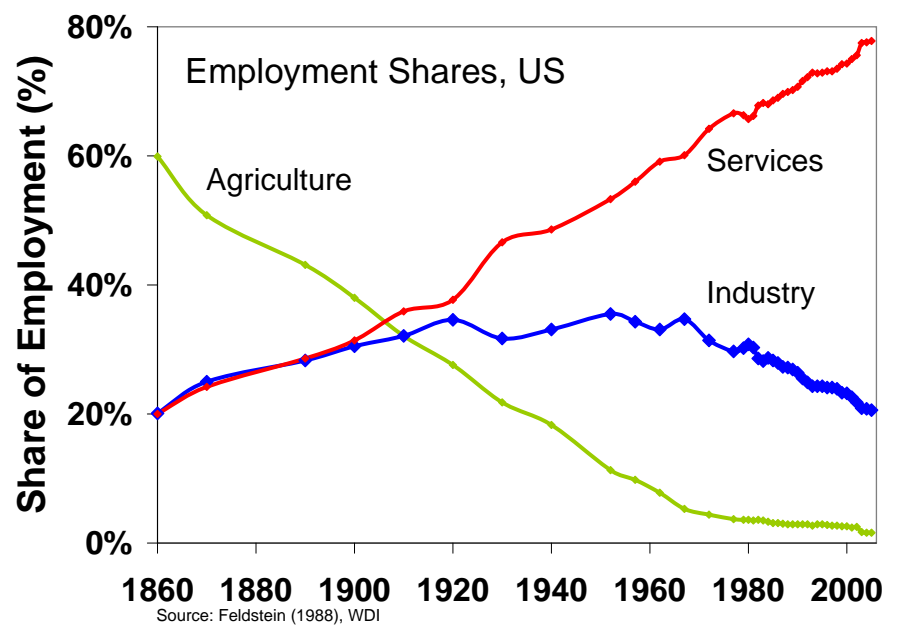

Figure 1.5: Employment share by sector in the US, 1860-2004.

More generally this patterns has been documented for employment shares and value added shares in cross-section and over time for individual countries. Maddison (1982) presents evidence for this process for 16 industrialized countries since 1820-1973 - Echevarria (1997) provides examples of this pattern holding in cross-section. More

\footnotetext{
12 Here, and in the rest of the paper unless noted otherwise, I divide sectors according to the standard ISIC III classification. Agriculture is defined to correspond to categories 1-5 (agriculture, forestry, hunting, and fishing). Industry corresponds to categories 10-45 (mining, manufacturing, construction, electricity, water, and gas) and services refers to categories 50-99 (wholesale, retail, transport, government,financial etc).

13 The countries are: Australia, Austria, Belgium, Canada, Denmark, Finland, France, Germany, Italy, Japan, Netherlands, Norway, Sweden, Switzerland, U.K., and USA
} 

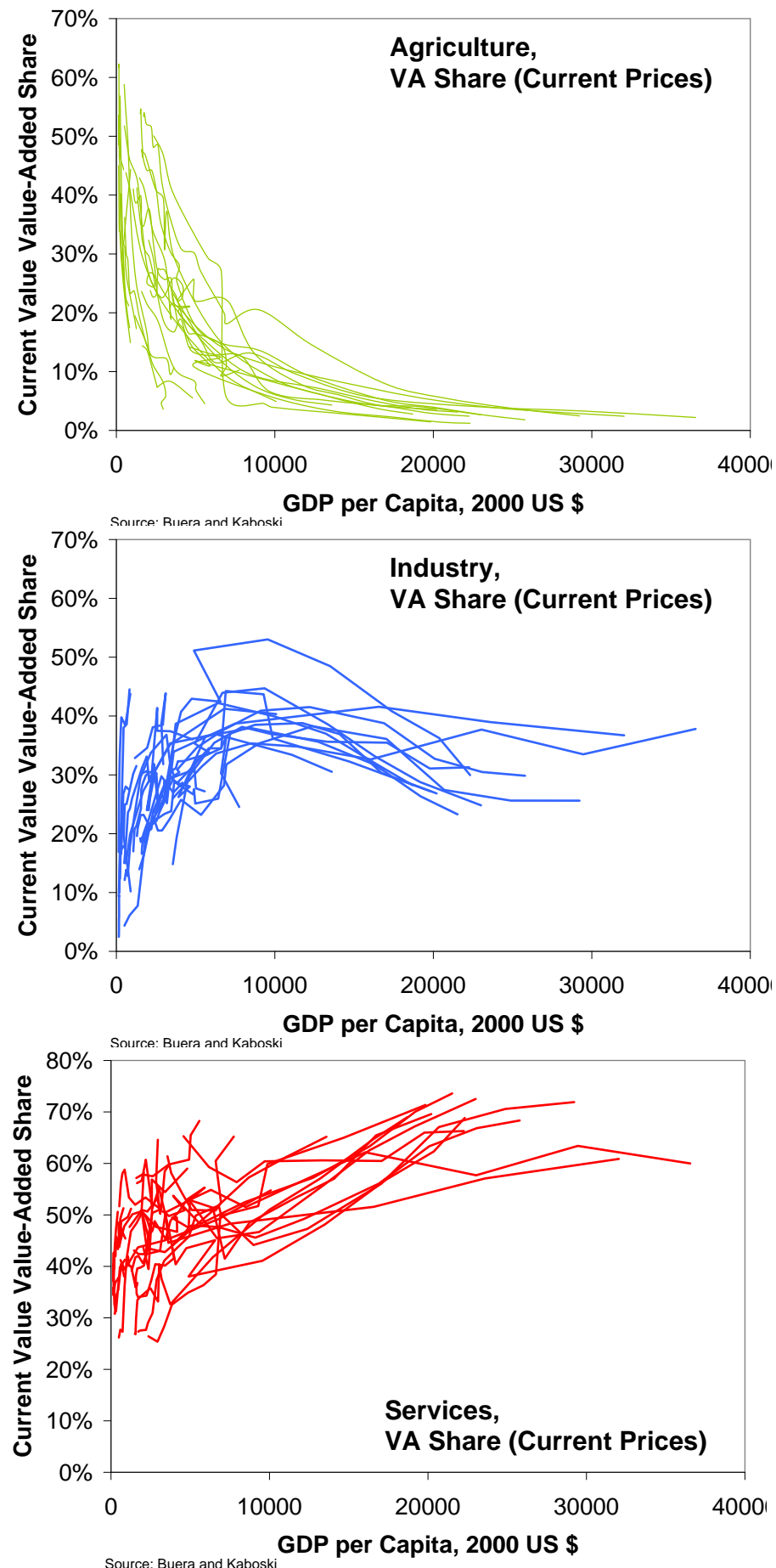

Figure 1.6: Sectoral Shares vs. Read GDP per capita (2000 US \$) for Country Panels 
recently, Duarte and Restuccia (2007) construct a panel of 29 countries 14 for the period 1956-2000 and document the structural transformation (and its influence on aggregate productivity) in each of the countries over time. Finally, Buera and Kaboski (2008) construct long run panel data that contains decade level data on current value share of GDP by major sector for 30 countries 15 from 1820 to 2001. Using their data, in Figure 1.6 I plot current price value-added shares in each of the sectors (Agriculture, Industry and Services) versus GDP per capita (in 2000 US dollars). Once again, the characteristic pattern of structural transformation is clearly visible.

\subsubsection{Changing sectoral oil intensities}

Next, I consider how oil intensities of individual sectors (agriculture, industry and services) change with a structural transformation. I run the following regression:

$$
\text { SectOilShare }_{i, t}^{s}=\beta_{0}+\beta_{1} \text { agrEmpShare }_{i, t}+\sum_{i=1}^{T-1} D_{i, t}+\varepsilon_{i, t},
$$

which relates the emission intensity of each sector $s=A, I, S$ in country $i$ at time $t$ (SectOilShare $\left.i_{i, t}^{s}\right)$, to how far countries are in the process of structural transformation. As before, I use employment in agriculture to index the progress of structural transformation $\left(\right.$ agrEmpShare $_{i, t}$ ). Since I am using panel data, I also include time specific dummies $\left(D_{i, t}\right)$ in the regression (one less than the total number of years). The data under consideration is for Australia, Canada, Denmark, France, Germany, Italy, Japan, the Netherlands, the UK and the US for the years 1970, 1972, 1975, 1977, 1980, 1985, 1986, 1990. For the years 1995 and 2000, the data consists of countries from the $\mathrm{OECD}^{16}$ as well as Argentina, Brazil, China, Israel, India, Indonesia and Russia and South Africa. The oil intensity by sector data, is derived from Input-Output tables constructed by the OECD $(2006)$ and is calculated by dividing the value of sectoral inputs

\footnotetext{
14 These include OECD countries such as Austria, Australia, Belgium, Canada, Denmark, Finland, France, Greece, Ireland, Italy, Japan, Korea, Netherlands, New Zealand, Norway, Portugal, Spain, Sweden, Turkey, U.K., and U.S. and Latin American countries such as Argentina, Bolivia, Brazil, Chile, Colombia, Costa Rica, Mexico, Peru, and Venezuela.

15 Argentina, Australia, Brazil, Canada, Chile, China, Colombia, Denmark, Egypt, France, Germany, India, Indonesia, Italy, Japan, Korea, Mexico, Netherlands, Norway, Pakistan/Bangladesh, South Africa, Spain, Sri Lanka, Sweden, Switzerland, United Kingdom, United States, Taiwan and Thailand

16 Here, taken to be Australia, Austria, Belgium, Canada, Czech Republic, Denmark, Finland, France, Germany, Greece, Hungary, , Ireland, Italy, Japan, South Korea, Luxembourg, the Netherlands, New Zealand, Norway, Poland, Portugal, Slovak Republic, Spain, Sweden, Turkey, UK and the USA
} 
Sectoral Oil Intensity vs. Agr. Share in Emp

\begin{tabular}{lccc}
\hline & $(1)$ & $(2)$ & $(3)$ \\
COEFFICIENT & Oil Int. Agr. & Oil Int. Ind. & Oil Int. Ser. \\
\hline agrEmpShare & $-0.0492^{* * *}$ & $0.0599^{* * *}$ & $0.0750^{* * *}$ \\
& $(0.0176)$ & $(0.0205)$ & $(0.0092)$ \\
Constant & $0.0519^{* * *}$ & $0.0411^{* * *}$ & $0.0154^{* * *}$ \\
& $(0.0044)$ & $(0.0051)$ & $(0.0022)$ \\
Observations & 104 & 104 & 104 \\
$R^{2}$ & 0.380 & 0.283 & 0.503 \\
\hline \multicolumn{4}{c}{ Standard errors in parentheses } \\
& $* * * \mathrm{p}<0.01,{ }^{* *} \mathrm{p}<0.05,{ }^{*} \mathrm{p}<0.1$ &
\end{tabular}

Table 1.2: Regression of sectoral oil intensities vs employment share in agriculture

in the category "Refined petroleum products, coke and nuclear fuel" by total sectoral value added 17 in a given country and year.

Table 1.2 shows the results. The significance is high in all three regressions. Furthermore, the changing structure of the economy can explain between $28 \%$ and $50 \%$ of sectoral emission intensities. Figure 1.7 shows the resulting regression lines (extended from 0\%-100\% employment shares in agriculture, for illustrative purposes). As a country structurally develops (i.e. as its share of employment in agriculture falls), sectoral oil intensity in agriculture increases and sectoral oil intensity in industry and service falls. The increase in oil intensity in agriculture can intuitively be explained as a movement away from traditional agriculture, towards mechanized agriculture (a tractor replaces a plough), whilst declining oil intensity in industry and services can arise from improvements in oil use efficiency (an advanced chemical processes that needs less oil as input, a more efficient generator or a bus that runs on hydrogen instead of oil).

\subsubsection{So, why the inverted-U aggregate oil intensity?}

This particular pattern of changing structure and oil intensity can result in an invertedU aggregate oil intensity curve. Consider Figure 1.7. In the early stages of structural

\footnotetext{
17 The category "Refined petroleum products, coke and nuclear fuel" corresponds to ISIC rev. 3 category 23. More disaggregated data would be desirable, however this was the most disaggregated, comparable cross-country input-output data that I could find.
} 


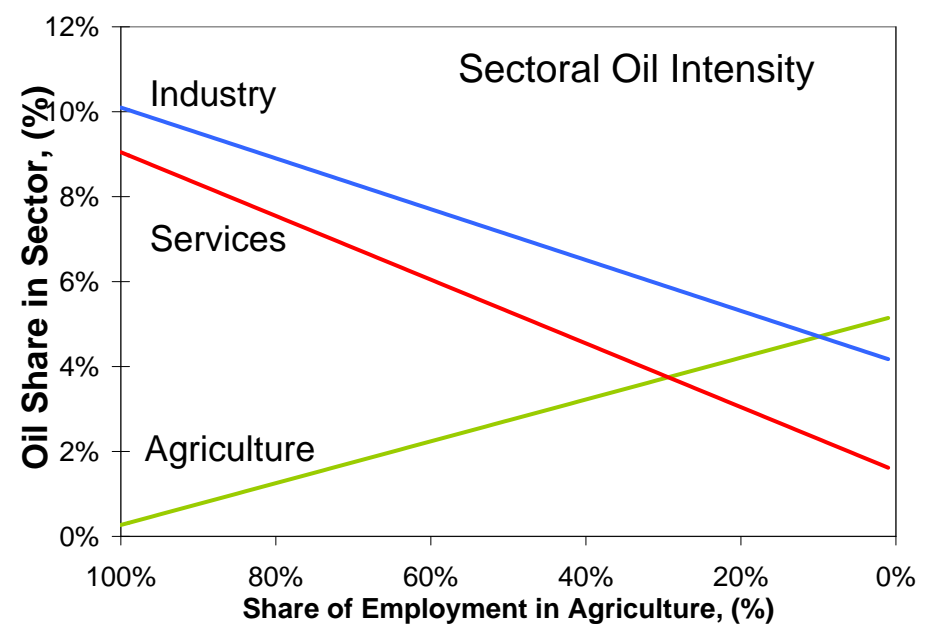

Figure 1.7: Sectoral oil intensities over structural transformation, regression lines. Extended from 0\%-100\% employment for illustrative purposes.

transformation, two factors contribute to rising oil intensity. First, the economy is shifting from predominantly oil unintensive agriculture towards oil intensive industry and services. Second, oil intensity of the largest sector - agriculture - is rising. Both of these developments contribute to rising aggregate oil intensity. In the late stages of structural transformation however, there are also two factors contributing to falling oil intensity. First, the economy shifts from oil intensive industry to (relatively) oil unintensive services. Second, the oil intensities of the largest sectors - industry and services - are falling. If oil intensity in agriculture rises slowly enough and oil intensity in industry and services falls fast enough, aggregate oil intensity can fall.

Notice however, that an inverted- $U$ is not - by any means - inevitable in the above setup. If in the late stages of structural transformation oil intensity in agriculture rises quickly enough, or oil intensity in non-agriculture does not fall fast enough, aggregate oil intensity may not fall. To a large extent the existence of an inverted-U aggregate oil intensity hinges on underlying parameters of the economy.

\subsubsection{Inelastically growing oil supply}

Figure 1.8 shows the total world output of oil from 1970-2007 and its Hodrick-Prescott trend BP (2008). Except for the period of OPEC driven oil shocks in the mid-1970's 


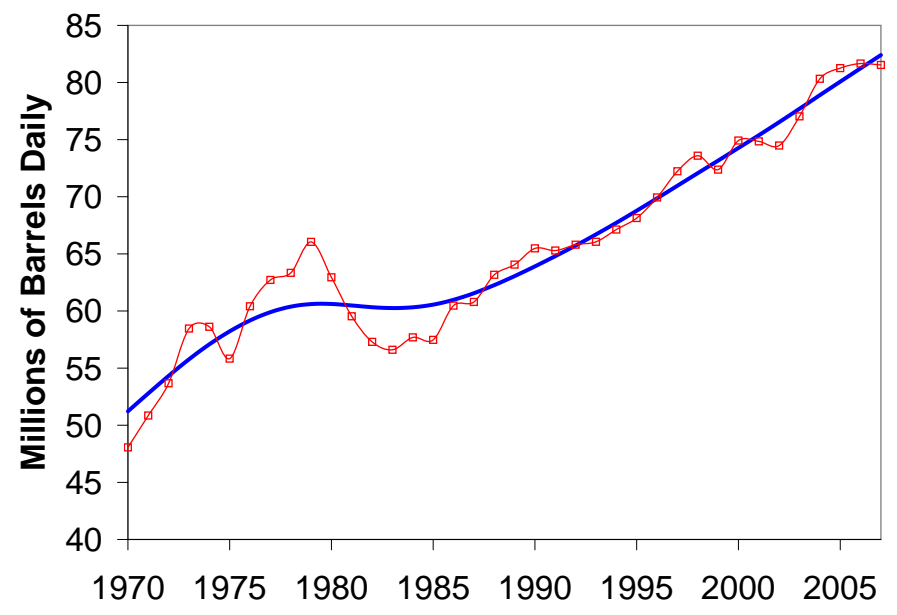

Figure 1.8: Total world oil production (and HP-trend), millions of barrels daily.

and early 1980's, the growth of oil output has been remarkably stable. This is especially evident for the period 1985-2007, where growth of world oil output is almost constant at $1.5 \%$ per annum.

Can oil output keep growing at this rate? There is a long history of studying the impact of an exhaustible resource on an economy. Dasgupta and Heal (1974), Solow (1974) and Stiglitz (1974) investigated the drag on economic growth caused by exhaustible resources. Gray (1914) andHotelling (1931) discussed the optimal extraction decision rules of producers when faced with an exhaustible resource. Yet, despite steadily growing world oil consumption over the past thirty years, the total quantity of confirmed reserves (the amount of oil left in the ground) has grown at and average annualized rate of $2.3 \%$ over the $1980-2007$ period BP (2008). This seems to indicate that even though the world is using ever more oil, improvements in location and extraction techniques have outpaced depletion. Of course, improvements in technology cannot continue to increase reserves indefinitely, since there is some physical upper bound on the quantity of reserves. However, the sheer quantity of oil left indicates that this may not be a problem in the short to medium run. A simple, back-of-the-envelope calculation that assumes that all confirmed reserves are usable, that no further new reserves will be found and that consumption of oil continues to grow at $1.5 \%$ per annum, indicates that the world will run out of oil by the year 2376. This estimate however, only refer to conventional 
oil reserves. The world contains enormous quantities of unconventional oil that can substitute for crude oil. For example, according to Campbell and Laherrre (1998), the Orinoco oil belt in Venezuela contains 1.2 trillion barrels of oil matter known as heavy oil - a quantity almost equal to all the worlds confirmed conventional oil reserves in 2007. Furthermore, tar sands and shale deposits in Canada and Russia may contain the equivalent of more than 300 billion barrels of oil.

As such, in this paper, I do not focus on the supply-side issue of exhaustibility, and the associated optimal extraction rules. Furthermore, I abstract from uncertainty within the oil supply framework (for example, uncertain political events) and from the imperfect competition that may be found in the oil sector in the guise of OPEC. Instead, I take the stand that world oil supply grows inelastically, that it will continue to do so into the future and that oil is supplied in a perfectly competitive environment. These simplifying assumptions allows the paper to focus on the impact of structural transformation on the demand for oil and how changing oil demand effects the world oil price.

\subsection{The Model}

The model is constructed to capture two facts visible in the data: 1) a shift of labor across sectors that characterizes structural transformation and 2) sector specific oil intensities that change with structural transformation. By the argument in section 1.2.7, after calibration these facts can result in an aggregate oil intensity curve in the shape of an inverted- $U$ - an aggregate oil intensity that first rises, then falls as countries structurally transform. Countries at the beginning of structural transformation (China/India) will observe rising oil intensity, whereas countries at the end of the structural transformation (OECD) will observe falling oil intensity. The model is then used to isolate the effect of rising oil demand caused by structural transformation in China/India on the oil price. Since the model focuses on capturing demand effects, oil supply is modeled as simply as possible - oil output is assumed to grow inelastically. 


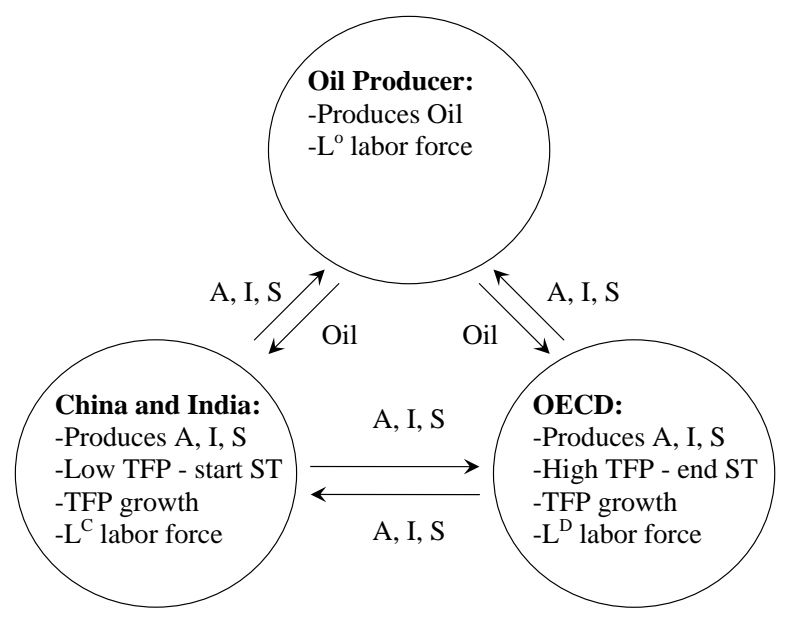

Figure 1.9: Structure of the Model

\subsubsection{The Economic Environment}

The model consists of three countries - China/India $(C)$, the OECD $(D)$ and an Oil Producer $(O)$. Country $O$ is the only producer of oil in the world economy 18 and furthermore, it only produces oil. China/India and the OECD are qualitatively identical. They are the only producers of agriculture $(A)$, industry $(I)$ and service $(S)$ goods in the world economy. Countries $C$ and $D$ trade these goods with each other, as well as with country $O$ in exchange for oil. Each country then consumes baskets of agriculture, industry and services, composed of $C$ 's and $D$ 's goods. Quantitatively however, China/India and the OECD $(i=C, D)$ can vary in: (1) initial levels of sector specific $\mathrm{TFP}^{19}, B_{s}^{i}$, for $s=A, I, S$; (2) sector specific TFP growth rates, $g_{s}^{i}$, for $s=A, I, S$; and (3) the size of their labor force, $L_{i}$. Finally, country $O$ is modeled as being small, in that its labor force, $L_{O}$, is significantly smaller than that of $C$ or $D$. Notice also, that the model is essentially a sequence of static problems, that vary from period to period through different (exogenous) levels of TFP. The structure of the model is summarized in Figure 1.9 .

\footnotetext{
18 It is easy to extend the model to include oil production in all countries, however this setup can represent the net-flows of oil. For example, even though the US and China are very large oil producers, they are also very large net oil importers.

19 The difference in sector specific TFP will result in countries being in different positions along their own structural transformations.
} 
Consumers' problems At each point in time $t$, the representative consumer in each country $i=C, D, O$ allocates income between goods by solving:

$$
\begin{aligned}
& \max G\left(A\left[A_{C}^{i}, A_{D}^{i}\right]-\bar{A}, I\left[I_{C}^{i}, I_{D}^{i}\right], S\left[S_{C}^{i}, S_{D}^{i}\right]\right) \\
& \text { s.t. } \sum_{j=C, D}\left(p_{A}^{j} A_{j}^{i}+p_{I}^{j} I_{j}^{i}+p_{S}^{j} S_{j}^{i}\right)=Y^{i} .
\end{aligned}
$$

In the above equation, $G$ is given by:

$$
G[A, I, S]=\left(\alpha_{A} A^{\rho}+\alpha_{I} I^{\rho}+\left(1-\alpha_{A}-\alpha_{I}\right) S^{\rho}\right)^{\frac{1}{\rho}},
$$

where, $\alpha_{A}$ is the utility weight on agriculture and $\alpha_{I}$ is the utility weight on industry and $\rho$ is the parameter that determines the elasticity of substitution between agriculture, industry and service goods. The consumer is endowed with an income of $Y^{i}$ in each period. In $i=C, D$ this consists of wage income from selling a unit of labor on the market, $Y^{i}=w^{i}$. For $i=O$, this is the income from oil sales, $Y^{O}=\frac{p^{O} O^{O}}{L^{O}}$, where $p^{O}$ is the price of oil and $L^{O}$ is the size of country O's labor force. Given income, the consumer in country $i$ chooses how many agriculture, industry and service goods produced in country $j$ he wishes to consume - $A_{j}^{i}, I_{j}^{i}$ and $S_{j}^{i}$ at price $p_{s}^{i}$, for each good $s=A, I, S$. The goods are then bundled together in each country using the following Armington aggregator:

$$
s[C, D]=\left(\nu_{s}^{i} C^{\gamma}+\left(1-\nu_{s}^{i}\right) D^{\gamma}\right)^{\frac{1}{\gamma}}
$$

where $\nu_{s}^{i}$ is country $i$ 's preference weight on country $C$ 's good. In particular, I assume that $\nu_{s}^{i}=1-\nu_{s}^{i^{\prime}}$ for $i=C, D$. That is, consumers place the same weight on their home goods. I also assume that $\nu_{s}^{O}=0.5$ - consumers in the oil producing country value both consumption goods equally.

In the model, structural transformation is driven by two channels: income effects arising from non-homothetic preferences as in Kongsamut et al. (2001) and substitution effects due to unbalanced productivity growth across sectors as in Ngai and Pissarides (2007).

The shift of labor away from agriculture towards other sectors is accomplished by introducing Stone-Geary, non-homothetic preferences in agriculture. In particular, it 
is assumed that there exists a subsistence level of consumption in agriculture, $\bar{A}$. It is easy to show that consumption of agriculture must always be at least as large as $\bar{A}$. At low levels of TFP, a high proportion of the labor force is devoted to agriculture in order to produce the required minimum. As TFP in the agricultural sector grows, less workers are needed to produce the subsistence level. These workers then shift away from agriculture towards the other two sectors.

The shift of labor away from industry towards services is accomplished by introducing an elasticity of substitution between sectors that is different from one. In particular, if TFP growth rates in Agriculture and Industry are higher than in the Service sector $\left(g_{A}, g_{I}>g_{S}\right)$ setting the elasticity of substitution between agriculture, industry and service goods low enough $\left(\frac{1}{1-\rho}<1\right.$, i.e. so that goods are gross complements) will result in labor moving away from agriculture and industry towards services in order to maintain a relatively stable proportion of consumption across types of goods20. If the service sector has a higher exogenous technological growth rate than the agriculture and industry sectors $\left(g_{S}>g_{A}, g_{I}\right)$, an EOS greater than one $\left(\frac{1}{1-\rho}>1\right)$ is needed to achieve the movement away from agriculture and industry towards services. During calibration, given TFP growth rates, the EOS is chosen to match the flow of labor from industry towards services.

Firms' problems At each point in time $t$, for $i=C, D$ and sectors $s=A, I, S$, firms solve the following problem:

$$
\max p_{s, t}^{i}\left(g_{s}^{i}\right)^{t} B_{s}^{i} F_{s}\left[O_{s, t}^{i}, L_{s, t}^{i}\right]-p_{o, t} O_{s, t}^{i}-w_{t}^{i} L_{s, t}^{i}
$$

where, $F_{s}[L, O]=\left(\eta_{s} O^{\xi_{s}}+\left(1-\eta_{s}\right) L^{\xi_{s}}\right)^{\frac{1}{\xi_{s}}}$. Notice, that both the initial sector-specific TFP levels, $B_{s}^{i}$, and the sector specific TFP growth rates, $g_{s}^{i}$, can all potentially vary across $C$ and $D$. The share of oil in sector specific production, $\eta_{s}$, and the elasticity of substitution between oil and labor, $\frac{1}{1-\xi_{s}}$, can vary across sectors (but not across countries).

Changing sector specific oil intensity is captured by introducing an elasticity of substitution between oil and labor in production, that is different from one. In particular,

\footnotetext{
20 If goods are gross complements, people like to consume goods in relatively fixed proportions. The only way to maintain fixed proportions when TFP growth varies across sectors is for labor to move from the faster growing sectors to the slower growing ones.
} 
choosing an elasticity of substitution that is greater than one in agriculture $\left(\frac{1}{1-\xi_{A}}>1\right)$ and smaller than one in industry and services $\left(\frac{1}{1-\xi_{i}}<1\right.$ for $\left.i=I, S\right)$ results in sectoral oil intensity that is rising in agriculture and falling in services. Since it is relatively easy to substitute between labor and oil in the agriculture sector, as countries structurally transform (and income per capita increases) the share of value added in agriculture devoted to oil will rise. Since substitution between oil and labor in the industry and service sectors is more difficult, as countries structurally transform (and income per capita increases) the share of value added in industry and services devoted to oil will fall. For more details see Appendix 1.9.2.

Notice, that since the sector specific elasticities of substitutions potentially differ across sectors, as the relative size of sectors changes (due to structural transformation), the aggregate oil-labor elasticity of substitution will also change. Thus, even though the elasticity of substitution between oil and labor is constant is constant in each sector, this is not necessarily the case at the aggregate level. Initially, when agriculture is the largest sector, the aggregate elasticity of substitution will mostly be determined by the elasticity of substitution in the agricultural sector. As the economy shifts towards industry and services, those sectors will have the largest impact on aggregate elasticity of substitution. A high elasticity of substitution in agriculture (greater than one) and a low elasticity in industry and services (less than one) will result in an aggregate oillabor elasticity of substitution that falls from above one to below one, as structural transformation takes place. In this way, aggregate oil intensity will first rise - up to a point - and then fall.

Oil production I model oil production by assuming an inelastically growing oil supply. This is done for simplicity and to keep the focus of the model on the demand effects of structural transformation on the oil price. I motivate this assumption by the stable growth of oil output observed over the past three decades. Each consumer in country $i=O$ is endowed with a fraction, $\frac{1}{L_{O}}$, of an inelastically growing stream of oil each period which he sells to the world:

$$
O_{t}^{O}=g_{O}^{t} B_{O}
$$

where, $B_{O}$ is an initial efficiency parameter. The total amount of available oil in the economy grows at a fixed and constant rate. Although the above production function 
might seem restrictive, the above can be viewed as a specialization of a model where labor combines with exogenously growing oil reserves to produce oil. In such a version of the model, the share of oil reserves would be 1 (see Appendix 1.9.3). In this sense, oil reserves are a fixed factor in oil production.

Market Clearing Finally, goods, labor and oil markets clear according to the following conditions:

$$
\begin{gathered}
\sum_{j=C, D, O} \bar{L}^{j} A_{i, t}^{j}=\left(g_{A}^{i}\right)^{t} B_{A}^{i} F_{A}\left[L_{A, t}^{i}, O_{A, t}^{i}\right] \\
\sum_{j=C, D, O} \bar{L}^{j} I_{i, t}^{j}=\left(g_{I}^{i}\right)^{t} B_{I}^{i} F_{I}\left[L_{I, t}^{i}, O_{I, t}^{i}\right] \\
\sum_{j=C, D, O} \bar{L}^{j} S_{i, t}^{j}=\left(g_{S}^{i}\right)^{t} B_{S}^{i} F_{S}\left[L_{S, t}^{i}, O_{S, t}^{i}\right] \\
L_{A, t}^{i}+L_{I, t}^{i}+L_{S, t}^{i}=\bar{L}^{i} \\
O_{t}^{O}=\sum_{i=C, D} \sum_{s} O_{s, t}^{i}=g_{O}^{t} B_{O} .
\end{gathered}
$$

Notice, that the size of the labor force across countries can potentially vary according to $\bar{L}^{i}$ for $i=A, D, O$. Thus, at each point in time, the total demand for $\operatorname{good} s=A, I, S$ made in country $i$ by country $j$ will be given by $\bar{L}^{j} s_{i, t}^{j}$ - the size of the labor force multiplied by the per-capita consumption.

Competitive Equilibrium For every $t$, a competitive equilibrium is: (1) A set of consumption good prices $\left\{p_{s, t}^{i}\right\}_{s=A, I, S}$ and wages $\left\{w_{t}^{i}\right\}$ for $i=C, D$ as well as oil prices $\left\{p_{O, t}\right\}$; (2) household allocations $\left\{s_{t}^{i}\right\}_{s=A, I, S}$, for $i=C, D, O$; and (3) firm allocations $\left\{L_{s_{t}}^{i}\right\}_{s=A, I, S}$ and $\left\{O_{s_{t}}^{i}\right\}_{s=A, I, S}$ for $i=C, D$, such that: (a) Given prices, (1), households' allocations, (2), solve the households problem (1.3); (b) Given prices, (1), firms' allocations, (2), solve the firms problem in Equation (1.6) ; and (c) good, labor and oil markets clear. Standard arguments ensure that an equilibrium exists and is unique. 


\subsection{Calibration of the Model}

The model is calibrated to match several facts pertaining to China/India and the OECD over the 1970-2003 period 21 . In particular, the above model is calibrated to match: 1) the structure of employment in China/India and the OECD in 1970;2) the structure of oil consumption in China/India and the OECD in 1970; and 3) observed sectoral TFP growth in China/India and the OECD for the years 1970-2003. The calibration is undertaken in three step $2^{22}$. First, sector and country specific labor growth rates and initial productivity levels as well as labor force sizes are calculated from the data $\left(g_{s}^{i}, B_{s}^{i}, \bar{L}^{i}\right)$. Next, the parameters governing the structural transformation are chosen $\left(\bar{A}, \alpha_{A}, \alpha_{M}, \rho\right)$. Finally, parameters affecting sector specific oil intensities are chosen $\left(\eta_{s}, \xi_{s}\right)$ as well as the parameters effecting trade in oil and goods $\left(\nu_{s}^{i}, \gamma\right)$.

Productivity and Labor Force Parameters Ideally, I would obtain total factor productivity by finding the following residual in the data:

$$
B_{s, t}^{i}=\frac{Y_{s, t}^{i}}{\left(\eta_{s} O_{s, t}^{i} \xi_{s}+\left(1-\eta_{s}\right) L_{s, t}^{i \xi_{s}}\right)^{\frac{1}{\xi_{s}}}},
$$

where $Y_{s, t}^{i}$ is a country $i$ 's sector $s$ gross output, $O_{s, t}^{i}$ is its oil use and $L_{s, t}^{i}$ is its labor force. Data on sectoral oil use and gross output however, is available only for limited countries and only for two years for China and India - 1995 and 2005. Consequently, I choose $B_{s, t}^{i}$ in the model to match labor productivity data (for details see Appendix 1.9.4. Calculating the sequences of TFP in this way, I can find the annualized growth rate of the productivity, for all countries and for all sectors 23 .

The output growth rate of the oil sector is calculated from world oil production data for the year 1970-2003, with the initial level of oil normalized to 1. The labor force in $O$ is set to be small relative to the Chinese/Indian labor force - it is chosen to be $5 \%$ of Chinese/Indian labor force. Finally, I normalize the labor force in $D$ to 1 , and set

\footnotetext{
21 The OECD here is taken to be Australia, Austria, Belgium, Canada, Denmark, Finland, France, Greece, Italy, Japan, Netherlands, New Zealand, Norway, Portugal, Spain, Sweden, Turkey, UK, US. These countries are chosen due to data availability.

22 Technically, this division is artificial since all the parameters are calibrated simultaneously. The division however, is made to ease exposition.

23 This is done by solving, $g_{s}^{i}=\left(\frac{B_{s, 2003}^{i}}{B_{s, 1970}^{i}}\right)^{\frac{1}{2003-1970}}$.
} 


\begin{tabular}{crrrc}
\hline & \multicolumn{3}{c}{ Values } & \\
\cline { 2 - 4 } Parameter & China & OECD & Oil Prod. & Target \\
\hline$B_{A, 1970}^{i}$ & 0.12 & 5.05 & - & Initial Prod. in $A$ \\
$B_{I, 1970}^{i}$ & 0.51 & 17.14 & - & Initial Prod. in $I$ \\
$B_{S, 1970}^{i}$ & 0.50 & 20.68 & - & Initial Prod. in $S$ \\
$g_{A}^{i}$ & 1.028 & 1.029 & - & Prod. growth in $A$ \\
$g_{I}^{i}$ & 1.051 & 1.020 & - & Prod. growth in $I$ \\
$g_{S}^{i}$ & 1.036 & 1.011 & - & Prod. growth in $S$ \\
$g_{O}^{i}$ & - & - & 1.014 & World oil output growth \\
$\bar{L}^{i}$ & 2.35 & 1 & 0.05 & Size of Labor force, 1970 \\
\hline \hline
\end{tabular}

Table 1.3: TFP, TFP growth rates and labor force parameter values and targets in a multi-country model.

the size of the labor force in $C$ to match the size of the labor force in China and India relative to the OECD in 1970. The results from the first step of the calibration are given in Table 1.3 .

Structural Transformation Parameters Parameters $\bar{A}, \alpha_{A}, \alpha_{I}$ and $\rho$ are chosen to match China/India's and the OECD's employment distribution across sectors in 197024 . The first two parameters influence employment levels in agriculture in the two regions. A high subsistence level in agriculture, $\bar{A}$, means that China/India - with their relatively low TFP in agriculture - must devote a large share of their labor force to agriculture. For the OECD, where the TFP in agriculture is significantly higher, this parameter plays a smaller role (with high agricultural TFP it is easy to achieve the subsistence level in the OECD). Instead, employment in agriculture is primarily determined by the utility parameter, $\alpha_{A}$ - the more consumers enjoy agriculture, the higher the employment in agriculture in the OECD. The utility weight on industry, $\alpha_{I}$, plays a similar role in influencing industrial employment in China/India. The more consumer's enjoy industrial goods, the higher the industrial employment in China/India. Finally, the employment in industry in the OECD is determined by the parameter $\rho$, which governs the elasticity of substitution between agriculture, industry and services. Given the OECD's higher TFP in industry and services in 1970, consumers in the OECD

\footnotetext{
24 Since the number of workers is fixed in each country, by matching employment shares in two sectors, I automatically match employment in the third sector.
} 
will consume more industry and more service goods than consumers in China/India. Exactly how much more of each type of good is consumed in the OECD, is influenced by the elasticity of substitution between goods in the utility. This, in turn, influences the quantity of workers employed in industry. The results from the second step of the calibration are given in the first part of Table 1.45 .

Oil Intensity Parameters I choose oil parameters, $\xi_{s}$ and $\eta_{s}$ to match the share in world oil consumption of every sector (in each country) in 197026 . It follows from the firm's first order conditions that at any point in time, the sectoral oil-labor ratio in each country is given by:

$$
\frac{O_{s, t}^{i}}{L_{s, t}^{i}}=\left(\frac{\eta_{s}}{1-\eta_{s}}\right)^{\frac{1}{1-\xi_{s}}}\left(\frac{w_{t}^{i}}{p_{t}^{O}}\right)^{\frac{1}{1-\xi_{s}}} .
$$

Since the oil price in both countries is the same, the oil labor ratio at each point in time, depends only on the relative wage of each country. Since sectoral employment in each country in 1970 is pinned down by the structural transformation parameters, by choosing oil-labor elasticity and share parameters, I can set the oil consumption of each sector in each country in 1970. At every point in time, a country with a higher per-capita income (recall that in $\mathrm{C}$ and $\mathrm{D}$, all income is wage income) will use more oil per worker in every sector. The sector specific elasticity of substitution between oil and labor, $\sigma_{s}=\frac{1}{1-\xi_{s}}$, determines how much more oil per worker richer countries use. With Cobb-Douglas production functions (with an elasticity of substitution between oil and labor of 1), a country with a higher nominal wage will have a proportionally higher oil-labor ratio. With lower elasticities of substitution, richer countries will have less

\footnotetext{
25 Notice, that since the model is being matched to the employment shares in China/India and the OECD in 1970, it doesn't exactly match the evolution of employment shares over time in either country, however it does a fair job of approximating shares in both countries over time. There is a trade off in how well the model matches structural transformation in any given country versus how well it matches the structural transformation in both countries - the better match the model makes in one country the worse it fares in matching the other country.

26 The strategy of matching oil consumption at one point in time in two countries, rather than at two points in time in one country arises from the inability of the model to match exactly the structural transformation at all points in time in both countries. There is a trade off between our ability to match the structural transformation in one country exactly whilst failing to match the structural transformation of the other, and doing a fair job of matching structural transformation in both countries. Since I choose the latter strategy, it would be incorrect to calibrate the oil parameters across time rather than across countries.
} 


\begin{tabular}{crc}
\hline & & Target \\
\hline $\bar{A}$ & 0.08 & Empl. in Agr. in C \\
$\alpha_{A}$ & 0.001 & Empl. in Agr. in D \\
$\alpha_{I}$ & 0.09 & Empl. in Ind. in C \\
$1 /(1-\rho)$ & 0.34 & Empl. in Ind. in D \\
$1 /\left(1-\xi_{A}\right)$ & 1.61 & Trend of Agr. Oil Int. \\
$1 /\left(1-\xi_{I}\right)$ & 0.72 & Trend of Ind. Oil Int. \\
$1 /\left(1-\xi_{S}\right)$ & 0.57 & Trend of Ser. Oil Int. \\
$\eta_{A}$ & 0.017 & Long Run Agr. Oil Int. \\
$\eta_{I}$ & 0.044 & Long Run Ind. Oil Int. \\
$\eta_{S}$ & 0.021 & Long Run Ser. Oil Int. \\
$\nu_{A}^{i}$ & 0.89 & Trade share in Agr., $i=C, D$ \\
$\nu_{I}^{i}$ & 0.66 & Trade share in Ind., $i=C, D$ \\
$\nu_{S}^{i}$ & 0.91 & Trade share in Ser., $i=C, D$ \\
$1 /(1-\gamma)$ & 1.9 & Change in share in world oil consumption \\
\hline \hline
\end{tabular}

Table 1.4: Preference, production and trade parameter values and targets in a multicountry model.

than proportionally larger oil to labor ratios, whilst with higher elasticities, they will have a more than proportionally larger oil to labor ratios.

Since total world oil supply is exogenous, only five of the six oil parameters are needed to match the shares of all sectors in world oil consumption at a point in time. As such, the elasticity of substitution between oil and labor is set to lie in the mid-range of the values estimated by Berndt and Wood (1975) and Griffin and Gregory (1976), $\sigma_{M}=0.72$. Due to a lack of data on oil consumption by sector in 1970 for all countries in the sample, I use the cross-sectional properties of sectoral oil intensity at different stages of structural transformation to infer sectoral oil consumption (see Appendix 1.9.5). The results from the third step of the calibration are given in the second part of Table 1.4 .

The calibration has the intuitive implication that industry uses the most oil $\left(\eta_{I}=\right.$ $0.044)$, followed by services $\left(\eta_{S}=0.021\right)$ and agriculture $\left(\eta_{A}=0.017\right)$. It also implies that oil and labor are (gross) substitutes in agriculture and (gross) complements in industry and services - with the lowest elasticity in the service sector. How robust is this result? I check, by re-estimating these elasticities using equation (1.14) (for details see Appendix 1.9.6). I use 1995 cross-sectional data and estimate the elasticity 
of substitution between oil and labor to be approximately 1.3 for agriculture, 0.63 for industry and 0.47 for services. The calibrated values lie in the empirically estimated ranges.

Broadly speaking, the approach for estimating these values in the literature is similar to mine. For example, Berndt and Wood (1975) use time-series data (1947-71) to estimate the factor share functions (arising from a transcendental logarithmic production function) in US manufacturing for four inputs - capital, labor, energy and materials - using iterative three-stage least squares. Griffin and Gregory (1976) perform a similar analysis for cross-country manufacturing data. How do my values compare to the values obtained in the literature? For agriculture, Shankar et al. (2003) estimate the Allen partial elasticity of substitution between energy and labor to be 4.58 in Hungary. This is higher than in our calibration, but of the same order of magnitude. Furthermore, the authors use a short time period and one that included significant political upheaval in Hungary. Next, in industry numerous studies find Allen partial elasticities of substitution between energy and labor to be less than one. Berndt and Wood (1975) estimates this elasticity for the US to be 0.65 . Griffin and Gregory (1976) estimates the elasticity for numerous advanced European countries and for the US to be between 0.72 and 0.87. Kemfert (1998) as well as Kemfert and Welsch (2000) estimate this elasticity for Germany to be 0.871 . These values are again of similar magnitude to the value 0.72 found in my calibration. Finally Koschel (2000) finds elasticity in the German service sector to be 0.28 . This again roughly matches the magnitude in our model estimates.

This pattern of constant sectoral oil-labor elasticities will result in a falling aggregate oil-labor elasticity of substitution. As the size of the high elasticity, agriculture sector declines and that of the low elasticity, industry and service sectors rises, aggregate oillabor elasticity of substitution will fall from above one to below one. This is consistent with the findings in the literature. In particular, Daragay (1992) estimates a significant reduction in the energy-GDP elasticity in the UK from 1.0 to 0.9 for 1973 and 1988, which he primarily explains by a decline in the relationship between industrial energy consumption and GDP.

Trade Parameters The home bias parameters in $i=C, D$ are chosen to match trade flows between these countries. The home bias parameters in $O$ are set to 0.5 - the oil 
producer shows no preference for $C$ 's or $D$ 's good. Finally, I choose the elasticity of substitution between $C$ 's and $D$ 's goods to match the change in the share in world oil consumption of China/India and the OECD over the 1970-2003 period. The results from the third step of the calibration are given in the third part of Table 1.4 .

Aggregate Oil Intensity, Oil Prices and World Oil Shares The calibration gives further insight into the two channels driving the inverted-U shape of the aggregate oil intensity curve visible in the data.

First, the pattern of oil use across sectors $\left(\eta_{I}>\eta_{S}>\eta_{A}\right)$ implies that as the economy moves away from producing predominantly agriculture to producing predominantly industry and service goods, aggregate oil intensity rises because of the higher oil use of these two sectors. As structural transformation continues and the economy moves from the high oil use industry sector to the (relatively) lower oil use service sector, aggregate oil intensity falls.

Second, the pattern in the sector specific elasticities of substitution between oil and labor $\left(\sigma_{A}>1>\sigma_{I}>\sigma_{S}\right)$ acts to enforce the first effect. As the economy moves away from agriculture (a sector with an elasticity of substitution that is greater than one) to industry and services (sectors with elasticities of substitution that are less than one), the aggregate elasticity of substitution falls from above to below one. Since in each country, labor is supplied inelastically in the aggregate, but the world supply of oil grows inelastically, oil - over time - becomes relatively more abundant. An initially high elasticity of substitution between oil and labor implies that the aggregate share of the factor becoming relatively abundant - oil - rises. As the elasticity drops below one, and it becomes more difficult to substitute between oil and labor, the aggregate share of the factor becoming relatively scarce - labor - rises. Consequently, at this stage, the aggregate share of oil falls.

Notice, that these effects operate on country-specific aggregate oil intensities through both the price and quantity channels. The price channel is straightforward. Since the output of oil grows inelastically, at the aggregate level, oil markets can only clear when, if faced with higher or lower international oil demand, oil prices either rise or fall respectively. As world demand for oil first rises and then falls world oil prices that follow 
an inverted-U shap 27 . The quantity channel is a bit more subtle. Even though at the world level, oil supply grows inelastically, from a single country's perspective oil supply is elastic. Consequently, if China/India's demand for oil grows faster than world oil output, prices are not the only channel to clear the market domestically. China/India can physically consume more oil if the OECD consumes less. Although, over time, the world is consuming an inelastically growing quantity of oil, China and India's share in world oil consumption is increasing. Taken together, these effects account for: 1) An inverted-U shaped aggregate oil intensity 2) An inverted-U shaped oil price curve 3) China and India's rising share in world oil consumption.

\subsection{Quantitative Analysis of Model}

In this section I first examine the path of structural transformation in China/India and the OECD implied by the model. Next, I consider how sectoral oil intensities change over time. Then, I consider how changing structure and sectoral oil intensities influence aggregate oil intensities in the model. Finally, I show how changing oil intensities result in changing world oil consumption shares and a hump shape oil price.

The model is run from 1970 to 2050. This requires assumptions on future sectoral productivity growth rates in both regions, and the future growth rates of oil output beyond the 1970-2003 period. Initially, I make the following assumptions about growth rates: 1) productivity growth rates in the OECD stay at their 1970-2003 levels, 2) productivity growth rates in China/India stay at their 1970-2003 levels until the level of sector specific TFP in the OECD is reached, at which point they drop to those in the $\mathrm{OECD}^{28}$ and 3) the growth rate of oil output remains at the level of the 1970-2003 period 29 .

\footnotetext{
27 Although world demand for oil first rises then falls, the world quantity demanded does not since in equilibrium world quantity demanded is always the same as world quantity supplied, and world quantity supplied of oil grows inelastically.

28 Notice, that this assumption is made to prevent China/India's TFP becoming too large relative to that of the OECD, however it never gets used in the model. In particular, despite the higher TFP growth rates, China/India's TFP does NOT catch up to the TFP in the OECD by 2050. Thus, effectively, in the time period under consideration China/india's TFP is assumed to at the same rate as it did over the 1970-2003 period. This process is chosen for simplicity and a more complicated technology diffusion process does not effect the results significantly.

29 In effect, I take the optimistic view that the world will not "run out of oil". Improvements in either extraction or location technology will ensure an inelastically growing oil supply in the coming
} 
The top two panels of Figure 1.10 show the changing shares of employment in China/India and the OECD over time. In China/India, employment share in agriculture falls, forms an inverted-U in industry and rises in services. In the OECD, a similar pattern emerges for agriculture and services. Since the OECD has higher TFP levels, it is further along the structural transformation. As such, the share of employment in industry is falling - it is on the downward part of the inverted-U industry employment curve.

The middle two panels of Figure 1.10 show sector specific oil intensities. Oil intensity is rising in agriculture, but falling in industry and services. This development is analogous to the development of oil intensities in the data shown in Figure 1.7. Intuitively, as agriculture becomes more mechanized, oil intensity in agriculture rises. As technology in non-agriculture improves, industry and services require less oil and oil intensity in those sectors drops.

The bottom two panels of Figure 1.10 show the aggregate oil intensities over time in China/India and the OECD. As China/India undergoes its structural transformation from beginning to end, aggregate oil intensity in China/India first rises and then falls forming an inverted-U. As the OECD finishes its structural transformation, we only see the second part of the inverted-U - falling aggregate oil intensity in the OECD.

The top four panels of Figure 1.10, help explain the patterns in aggregate oil intensity visible in the bottom two panels. Initially in China/India, as the economy shifts away from agriculture towards industry and services, aggregate oil intensity rises, since sectoral oil intensity in industry and services is significantly higher than in agriculture. This effect is reinforced by rising oil intensity in the largest sector - agriculture. Later in both China/India and the OECD, the structural transformation becomes dominated by a shift away from industry towards services. Since oil intensity in services is lower than in industry, aggregate oil intensity falls. This effect is reinforced by falling oil intensities in the largest two sectors - industry and services.

Figure 1.11(a) shows how changing aggregate oil intensity affects the share in world consumption of specific countries. Since the output of oil is growing inelastically, as China/India spend a rising share of their income on oil and the OECD spends a falling share of income on oil, China/India's share in world oil consumption increases and decades. 


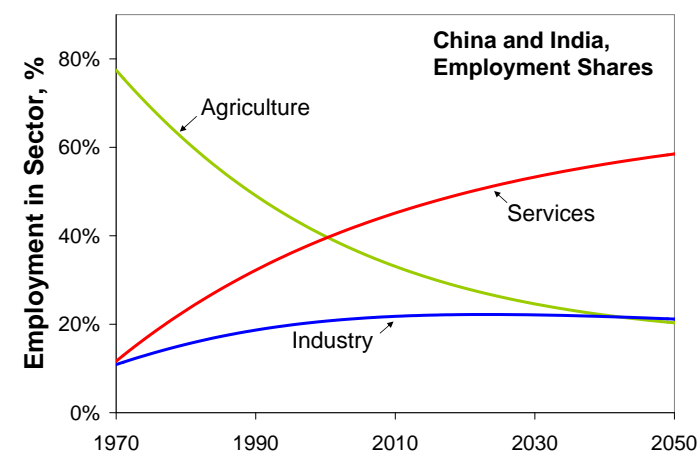

(a) China/India, Employment Shares

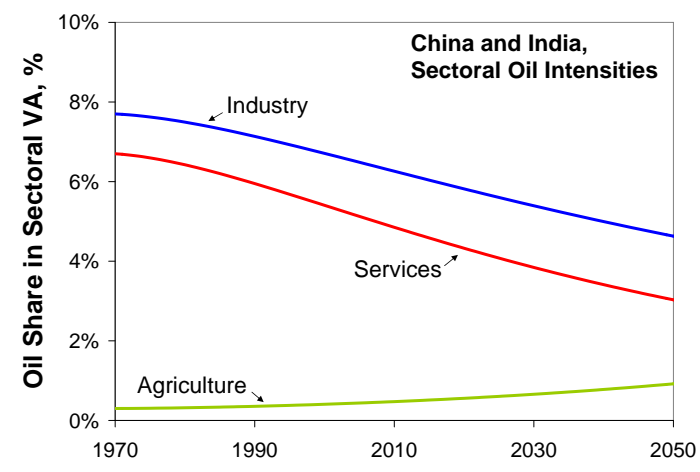

(c) China/India, Sectoral Oil Intensities

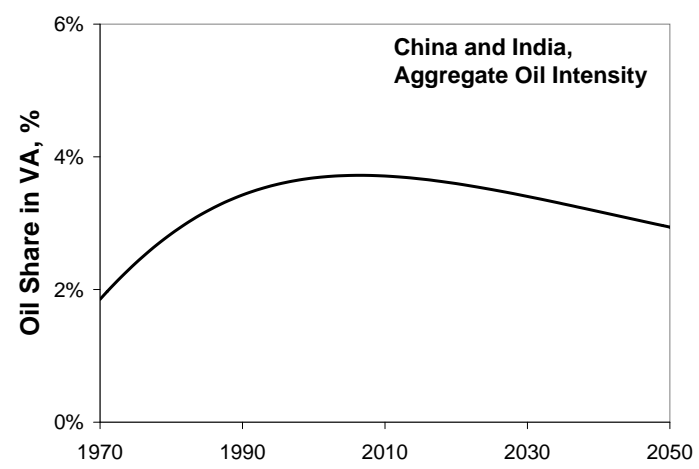

(e) China/India, Aggregate Oil Intensities

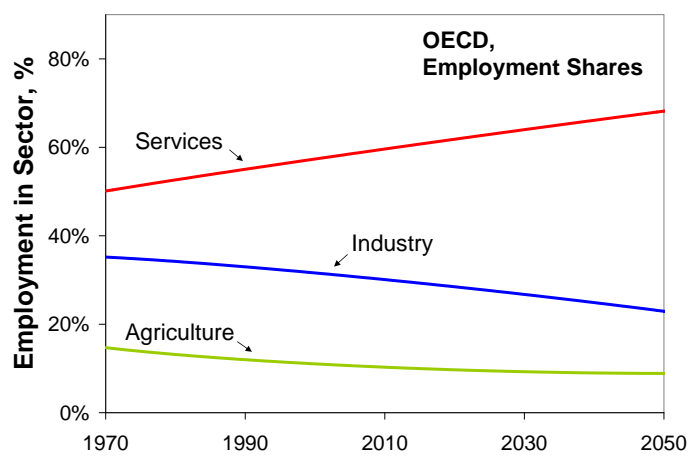

(b) OECD, Employment Shares

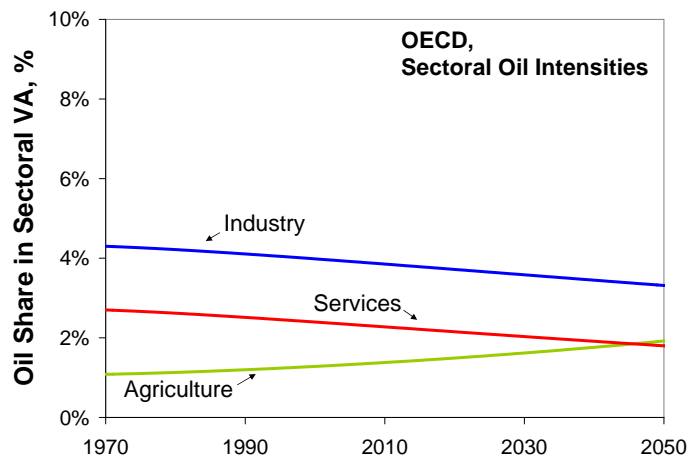

(d) OECD, Sectoral Oil Intensities

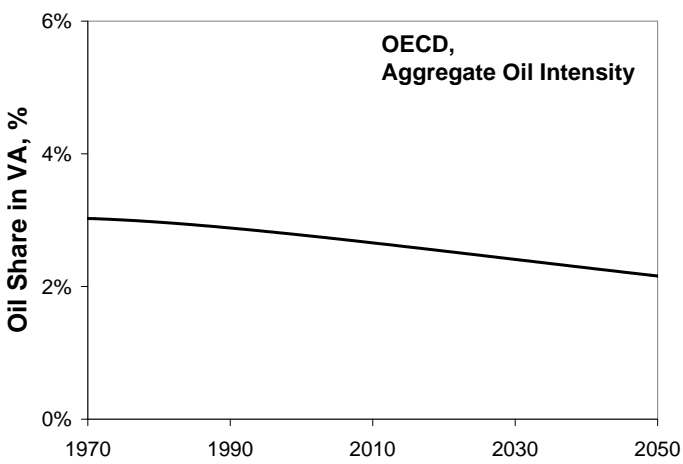

(f) OECD, Aggregate Oil Intensities

Figure 1.10: Simulation result for employment shares, sectoral oil intensities and aggregate oil intensities. 


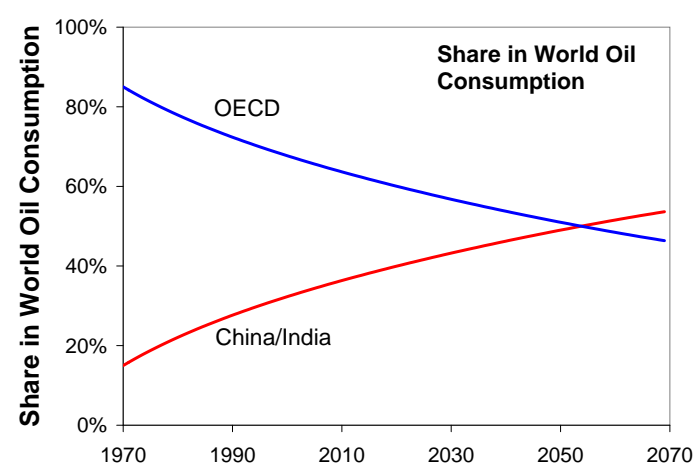

(a) Oil Consumption Shares

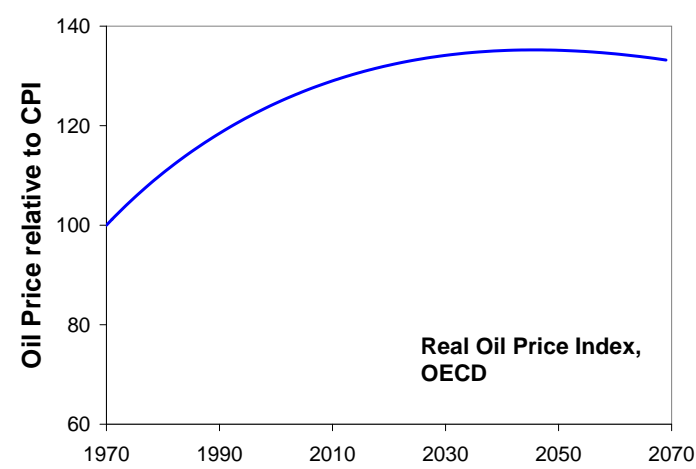

(b) OECD Oil Price

Figure 1.11: Share of oil consumption by region and OECD oil price.

the OECD's share falls. When China/India enters the second phase of the inverted-U aggregate oil intensity curve, both the shares spent on oil in the OECD and China/India are falling which results in shares that slowly begin to level off.

Finally, Figure $1.11(b)$ shows the wide hump in oil prices that arises from the hump in aggregate oil intensity in China/Indi2 30 . As China/India spends first a higher then a smaller fraction of its income on oil it induces the world's aggregate oil intensity to follow a hump shape as well. This causes oil prices to rise and fall around the world and more oil to moves towards China. The model predicts that prices will rise approximately $35 \%$ until the mid 2040's, as China undergoes its structural transformation. The model however, also predicts that as China finishes its structural transformation, it will spend a falling share of its income on oil, resulting in prices that will eventually start to decline.

\subsection{Counterfactuals}

In this section I perform two counterfactuals that gauge the effect of China and India's growth and structural transformation on oil prices and underline the importance of modeling oil prices within a multi sector framework, rather than in a regular one sector growth model.

In the first counterfactual I switch off productivity growth in China and India in

\footnotetext{
30 The price here, refers to the oil price in the model relative the to the OECD's time zero, fixed basket consumer price index.
} 


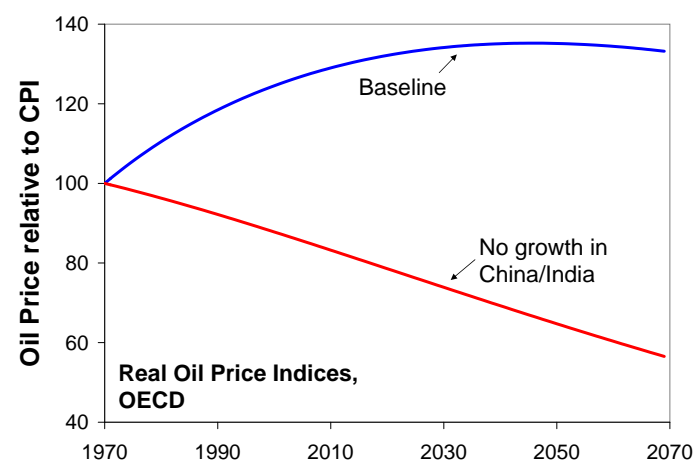

(a) No growth in China/India

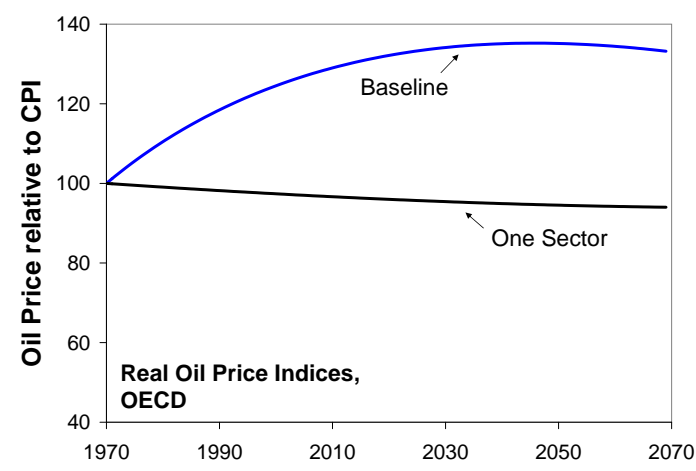

(b) One sector model

Figure 1.12: Counterfactual experiments.

all sectors and compare the resulting price index to the price index obtained in the baseline model. The result is shown in Figure 1.12(a). This experiment allows me to measure the total effect that growth and structural transformation in China and India have had on oil prices. From the graph, it becomes clear that if China and India had not undergone structural transformation at the speed that they did, oil prices would have declined since the 1970's. Comparing the two curves, the China/India effect results in oil prices in the model that are more than 100\% higher at their peak in 2046 than they would be without the China/India effect. Furthermore, according to the model, the oil price in the OECD is 50\% higher in 2007, than if China and India had not structurally transformed at the speed that they did. In this sense, the model explains $25 \%$ of the $200 \%$ observed increase in oil prices over the 1970-2007 period 31 .

Second, I replace all sector specific parameters with weighted sectoral averages of those values. In particular, I weigh country specific parameters (TFP growth rates and initial TFP levels) by the period zero current price share of each sector relative to each country's current price GDP. In particular, I set $g_{s}^{C}=1.031$ and $B_{s, 1970}^{C}=0.21$ in all three sectors in China/India and I set $g_{s}^{D}=1.017$ and $B_{s, 1970}^{D}=17.13$ in all three sectors in the OECD. Next, I replace all parameters that are common across countries but differ across sectors (production and trade parameters) by the sector

\footnotetext{
31 Notice, that even though these curves show oil price indices, they can also be viewed as normalized price levels since both models are the same in time zero.
} 
specific parameters weighed by the period zero current price shares of each sector in the OECD. In particular, I set $\sigma_{s}=1 /\left(1-\xi_{s}\right)=0.68, \eta_{s}=0.029$ and $\nu_{s}=0.82$. All other parameters remain the same as in the baseline. Since all parameters are now identical across sectors, the model is essentially a standard, open economy, one sector growth model. The above procedure effectively turns off structural transformation, whilst keeping growth effects. The resulting price index, is shown in Figure 1.12(b), from this, it becomes clear that that omitting structural transformation misses a crucial non-linearity in prices. Without structural transformation, oil prices would have fallen ${ }^{32}$

To see the source of this non-linearity, I demonstrate how aggregate elasticity of substitution between oil and labor in the baseline and in the one sector model change over time. In particular, taking the log of equation (1.14), I obtain a relationship that can be estimated from the data:

$$
\log \left(\frac{O_{s, t}^{i}}{L_{s, t}^{i}}\right)=\sigma_{s} \log \left(\frac{\eta_{s}}{1-\eta_{s}}\right)+\sigma_{s} \log \left(\frac{w_{t}^{i}}{p_{t}^{O}}\right) .
$$

In the above, $\sigma_{s}=\frac{1}{1-\xi_{s}}$, is the elasticity of substitution between oil and labor in sector $s$. Notice, that if there was only one sector in the economy, then $\sigma_{s}$ would be the aggregate elasticity of substitution between oil and labor. In particular, if an econometrician was given a sequence of relative wage and oil-labor ratio data derived from the baseline and the one sector model and asked to estimate $\sigma_{s}$ at each point in time under the assumption that the data come from a one sector economy, his estimates would reflect the aggregate elasticity of substitution between oil and labor at each point in time. Aggregate elasticities of substitution estimated in this way for China/India and the OECD in both models at each point in time are shown in Figure 1.15.

The econometrician in the one sector model would find that the elasticity of substitution between oil and labor is constant over time and across countries and is equal to $\sigma_{s}=0.68$. This is quite unsurprising, since in the one sector model, the aggregate elasticity of substitution does not change. On the other hand, the econometrician in the baseline world, would find that the estimates of elasticity of substitution vary widely

\footnotetext{
32 Notice, that since the models are different in the initial period, they can no longer be viewed as normalized price levels. However, it is still correct to compare the price dynamic over time between the two scenarios.
} 


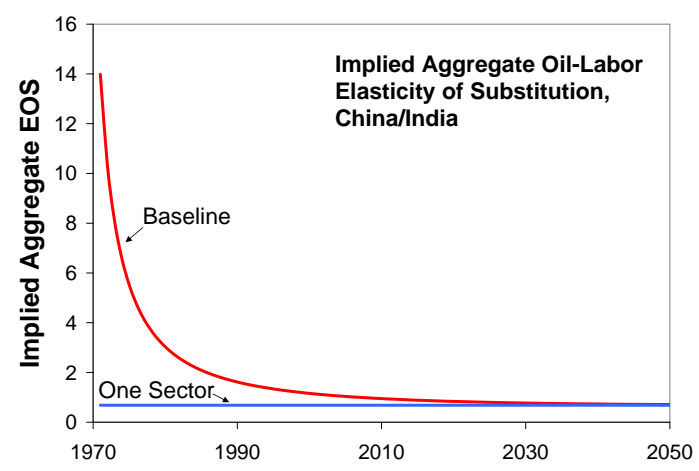

(a) China/India

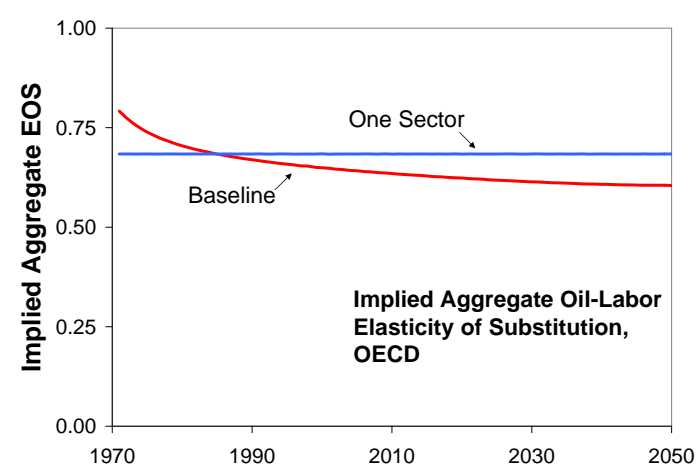

(b) OECD

Figure 1.13: Implied Aggregate Oil-Labor Elasticities of Substitution in China/India and the OECD in the Baseline and One Sector Models.

over time and between countries. In particular, in China/India, the elasticity of substitution is very high initially (above one) and drops over time (to below one). In the OECD, the elasticity of substitution is also dropping but remains strictly below one the entire period.

Why is aggregate elasticity of substitution changing in the baseline model but constant in the one sector model? Since each sector has a different elasticity of substitution, as the relative size of sectors change, the aggregate elasticity of substitution also changes. The model is thus capable of generating endogenously changing elasticities of substitution - something that the one sector model cannot do. In China/India, when the elasticity of substitution is above one, oil intensities rise (recall that with the elasticity higher than one, the share of the factor growing more scarce - oil - rises). When the elasticity of substitution falls below one, oil intensities fall (with an elasticity lower than one, the share of the factor growing more scarce - oil - falls). In the OECD, since elasticities are always below one, oil intensity is always falling. In the one sector model however, elasticities are the same in both countries and always below one - this results in oil intensities that are falling in both countries. The baseline model predicts a hump shape oil price that follows the hump shape of emission intensity, whereas a model that omits structural transformation predicts falling oil prices and hence gives misleading implications about the long-term oil price dynamics. The lesson here is that to understand the impact of growth on the oil price, it is crucial to take a more disaggregated 


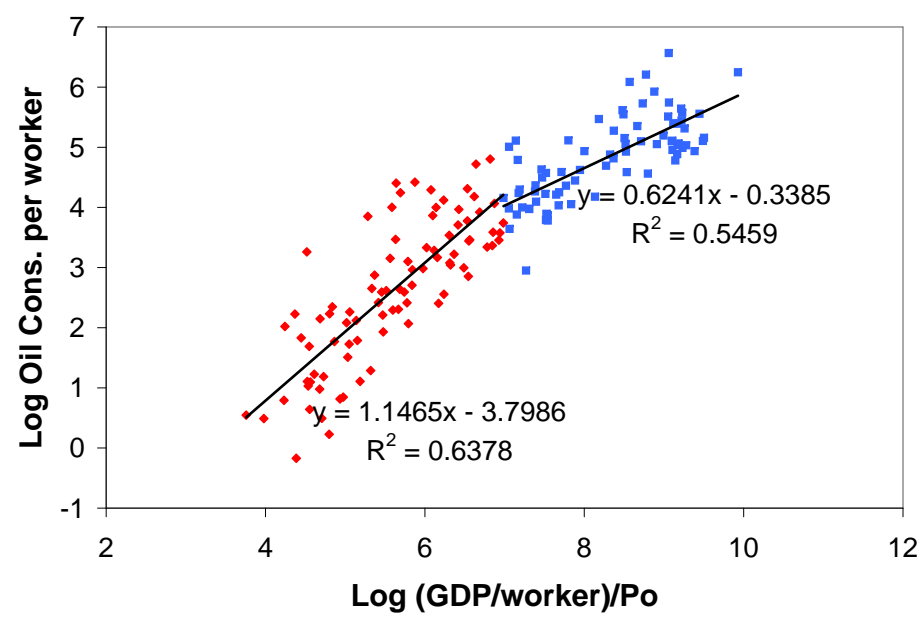

Figure 1.14: Evidence for falling aggregate oil-labor elasticity of substitution.

view than is standard in macroeconomics.

\subsection{Evidence}

Finally, I present evidence for aggregate oil-labor elasticities of substitution that fall from above to below one. In particular, I estimate equation (1.15) using cross-sectional 2000 data for all the world's countries, under the assumption that the data come from a one sector economy. Figure, 1.14 shows a log-log scatter plot of aggregate oil consumption per worker versus GDP per worker relative to the 2000 oil prick 33 . GDP and labor force data comes from WDI (2007) whilst oil consumption data comes from the EIA. The data has been divided into two groups of equal number of points, and regression lines have been drawn through each groups of the data. The slope of each regression line is an estimate of the aggregate elasticity of substitution between oil and labor at every level of wage-oil price ratio. Since, all countries face the same oil price, from the figure it is apparent that as income rises, elasticity of substitution fall from above to below one just as the model predicts.

\footnotetext{
33 In the model wages correspond to value added per capita. Since value added per capita data is not available for a wide selection of countries, I use GDP per capita instead.
} 


\subsection{Conclusion}

As structural transformation progresses, aggregate oil intensity first rises and then falls - forming an inverted-U shape. This can result in oil prices that follow a similar pattern over structural transformation. As large countries such as China and India enter the most oil intensive phases of their structural transformation, oil prices will rise. The increase however, is not necessarily permanent. In the medium to long run, the pressure on oil prices will ease, as the structural transformation in these countries comes to an end and oil intensity falls. Using a standard growth model model misses this non-linearity and can give misleading implications about the long-term oil price. To understand the impact of growth on the oil price, it is necessary to take a more disaggregated view than is standard in macroeconomics.

This paper is the the first to identify an inverted-U aggregate oil intensity curve in the data, the first to build a model that theoretically justifies its existence and the first to consider the long term price path implications of such a curve. The main contribution of the paper however, is to take a systematic approach to a contentious topic - China and India's impact on the oil price. In particular, the model developed here predicts that as long as the structural transformation in China/India and other developing nations follows past patterns, the upward pressure on oil prices from China and India will continue for many decades. Interestingly however, the model also predicts that in the more distant future, oil prices can return to lower levels as the economies of these countries become service dominated - hence China and India's impact on the oil price is not necessarily permanent.

\subsection{Appendix}

\subsubsection{Aggregate Oil Intensity}

I construct a panel data set that consists of the worlds largest 100 countries (by population in the year 2000) over the 1980-2005 period. Each data point is composed of: 1) a time period, 2) the share of employment in agriculture and 3) the aggregate oil intensity. The data for the shares of employment in agriculture comes from the WDI. The aggregate oil intensity of the economy is constructed by calculating the current year 
Agg. Oil Intensity vs. Agr. Share in GDP

\begin{tabular}{lcc}
\hline \multirow{2}{*}{ COEFFICIENT } & Aggregate Oil Int. (OLS) & $(2)$ \\
& & Aggregate Oil Int. (LAV) \\
\hline agrShare & $0.128^{* * *}$ & $0.094^{* * *}$ \\
& $(0.0066)$ & $(0.0056)$ \\
agrShareSq & $-0.165^{* * *}$ & $-0.114^{* * *}$ \\
& $(0.0095)$ & $(0.0080)$ \\
Constant & $0.0091^{* * *}$ & $0.0081^{* * *}$ \\
& $(0.0008)$ & $(0.0006)$ \\
Observations & 1172 & 1172 \\
$R^{2}$ & 0.2496 & 0.1731 \\
Pseudo $R^{2}$ & & \\
\hline
\end{tabular}

Standard errors in parentheses

*** $\mathrm{p}<0.01,{ }^{* *} \mathrm{p}<0.05,{ }^{*} \mathrm{p}<0.1$

Table 1.5: Regression of aggregate oil intensity versus the agriculture share in value added for a panel of 150 countries over the period 1995-2005.

value of oil consumed in an economy (in dollar terms), divided by the current year GDP of the country (in dollar terms). Total country-specific oil consumption (in Quadrillions of BTU) and current oil price (dollars per million BTU) data come from the EIA. The oil price used is the 30-year moving average. The shape of the curve remains unchanged if observed oil price data is used. but using unsmoothed oil price data results in oil intensities that are significantly higher due to the high oil prices shock in the early 1980's. Current value GDP (in dollar terms) comes from the WDI.

Next, I perform robustness exercises to check for the existence of an inverted-U aggregate oil intensity curve in the data. I estimate the following equation using Ordinary Least Squares and Quantile Regression (also known as Least Absolute Value):

$$
\text { AggrOilShare }_{i, t}=\beta_{1} \text { agrShare }_{i, t}+\beta_{2} \text { agrShare }_{i, t}^{2}+\varepsilon_{i, t} .
$$

The results are given in Table 1.5. All coefficients are highly significant and do not differ greatly across regression types. The $R^{2}$ values are approximately $7 \%$ and $4 \%$. Table 1.1, in the main body of the text, presents the results for the following regression: 


$$
\text { AggrOilShare }_{i, t}=\beta_{1} \text { agrShare }_{i, t}+\beta_{2} \operatorname{agrShare}_{i, t}^{2}+\sum_{j=1996}^{2005} \beta_{2008-j} D_{i, t}^{j}+\varepsilon_{i, t},
$$

where $D_{i, t}^{j}$ is a dummy variable that takes the value one if $j=t$ and zero otherwise. All coefficients remain highly significant. Adding dummies (unsurprisingly) increases the $R^{2}$ of the regressions.

\subsubsection{Matching sectoral oil intensities}

The oil intensity of sector $s$ - the share of oil relative to the value added of the sector can be written as a function of sector specific oil-labor ratios, $\frac{O_{s}}{L_{s}}$, oil-labor elasticity of substitution parameters, $\xi_{s}$ and the oil share parameters, $\eta_{s}$ :

$$
\begin{aligned}
\frac{p_{O} O_{s}}{V_{s}} & =\frac{p_{O} O_{s}}{w_{s} L_{s}} \\
& =\frac{p_{s} F_{s, O} O_{s}}{p_{s} F_{s, L} L_{s}} \\
& =\frac{\eta_{s} O_{s}^{\xi_{s}}}{\left(1-\eta_{s}\right) L_{s}^{\xi_{s}}}
\end{aligned}
$$

The first equality follows from the fact that oil is imported and is hence an intermediate input. Value added in a sector is consequently identical to wage income in that sector. The second equality follows from the profit maximization problem of a sector $s$ firm, since its production function is given by $g_{s}^{t} B_{s} F_{s}\left[L_{s, t}, O_{s, t}\right]$ where, $F_{s}[L, O]=\left(\eta_{s} O^{\xi_{s}}+\right.$ $\left.\left(1-\eta_{s}\right) L^{\xi_{s}}\right)^{\frac{1}{\xi_{s}}}$. Notice also that $F_{s, L}$ and $F_{s, O}$ refer to the derivatives of $F$ with respect to labor and oil respectively. Thus, the share of oil in value added in sector $s$ is given by:

$$
\frac{p_{O} O_{s}}{V_{s}}=\frac{\eta_{s}}{1-\eta_{s}}\left(\frac{O_{s}}{L_{s}}\right)^{\xi_{s}}
$$

Since this relationship holds at every point in time, I can choose $\eta_{s}$ and $\xi_{s}$, to match sectoral oil intensity at the beginning and end of of a structural transformation in each sector. In particular, $\xi_{s}$ will determine how fast sectoral oil intensity changes (i.e. its slope) and $\eta_{s}$ will determine the overall level of oil intensity (i.e. the long run oil intensity of the sector). 
What elasticity parameters allow us to match the cross-sectional oil intensities implied by the data (i.e. rising oil intensities in agriculture and falling oil intensities in industry and services)? As structural transformation progresses, the amount of labor in each sector changes relatively slowly. The total amount of oil in the economy, on the other hand, is growing at a fixed exogenous rate. The ratio, $\frac{O_{s}}{L_{s}}$, will thus eventually be increasing in all sectors. Setting $\xi_{A}>0$ in agriculture and $\xi_{I}, \xi_{S}<0$ in industry and services (and the appropriate $\eta_{s}$ 's) allows us to match observed cross-sectional oil intensities.

\subsubsection{Oil Production Function}

The oil production function, equation 1.7 re-written here:

$$
O_{t}^{O}=g_{O}^{t} B_{O}
$$

can be seen as a specialization of a Cobb-Douglas technology that combines labor, $\left(L_{O}\right)$, and oil reserves, $(R)$, to produce oil:

$$
\sum_{s=A, I, S} O_{s, t}=\bar{g}_{O}^{t} \bar{B}_{O}\left(g_{R}^{t} R\right)^{\varepsilon} L_{O, t}^{1-\varepsilon}
$$

In the above, $\varepsilon$ is the share of oil reserves in oil production, $g_{R}$ is the exogenous growth rate of oil reserves (or alternatively oil reserve location techniques), $\bar{g}_{O}^{t}$ is the exogenous growth rate of refinement technology and $\bar{B}_{O}$ is an initial efficiency parameter. Labor in the oil producing country is supplied inelastically and hence, $L_{O, t}=L_{O}$. I can thus re-write the production function as:

$$
\sum_{s=A, I, S} O_{s, t}=\left(\bar{g}_{O} g_{R}^{\varepsilon}\right)^{t}\left(\bar{B}_{O} R^{\varepsilon} L_{O}^{1-\varepsilon}\right) .
$$

By setting $g_{O}=\bar{g}_{O} g_{R}^{\varepsilon}$ and $B_{O}=\bar{B}_{O} R^{\varepsilon} L_{O}^{1-\varepsilon}$, I obtain my original production function given by equation (1.7). Thus, the growth rate of oil output depends on the (exogenous) innovation in the oil production industry and on (exogenous) growth in oil reserves 34 .

The assumption of the above production function, is that oil extraction does not impact the total quantity of oil reserves, $g_{R}^{t} R$. This assumption is made primarily for

\footnotetext{
34 No explicit assumption is made whether $g_{R}$ is greater or smaller than one, rather $g_{O}$ is chosen to match world oil production data. If we assume positive oil output growth, this can either mean that both $g_{O}$ and $g_{R}$ are greater than one, or that $g_{O}$ is sufficiently large to overcome depleting oil reserves.
} 
simplicity, and can be thought of as signifying that oil reserves are very large in comparison to extraction. Alternatively, this assumption can be interpreted through the prism of the (somewhat-controversial) abiotic theory of oil production. This theory promoted by Gold (1992) and recently documented by Proskurowski et al. (2008), suggests that coal and crude oil deposits arise from the decomposition of microbes living at extreme depths under the surface of the earth and drawing their energy from natural super-heated subterranean gas flows. In other words, this theory claims that oil - rather than being produced from the decomposition of exhaustible fossils - arises from tectonic forces and is continuously being replenished by the decomposition of new microbes.

Finally, if I choose to incorporate the more general version of the production function directly into the model, the consumer's problem in the oil producing country, will qualitatively change. Consumers will now own the oil reserves and the inelastically supplied labor, rather than owning a flow of oil output. As such, the consumer's income will no longer come from sales of oil, but rather from the supply of oil reserves and labor to oil producing firms as well as the profits of those firms. Quantitatively however, this proves to be identical to the original problem, since firms earn zero-profits.

\subsubsection{Total Factor Productivity Calibration}

Ideally, I would obtain total factor productivity by finding the following residual in the data:

$$
B_{s, t}^{i}=\frac{Y_{s, t}^{i}}{\left(\eta_{s} O_{s, t}^{i} \xi_{s}+\left(1-\eta_{s}\right) L_{s, t}^{i} \xi_{s}\right)^{\frac{1}{\xi_{s}}}}
$$

where $Y_{s, t}^{i}$ is a country $i$ 's sector $s$ gross output, $O_{s, t}^{i}$ is its oil use and $L_{s, t}^{i}$ is its labor force. Data on sectoral oil use and gross output however, is available only for limited countries and only for two years - 1995 and 2005 . Consequently, I estimate sectoral productivity growth data using labor productivity data.

Labor productivity in the data is given by:

$$
\bar{D}_{s, t}^{i}=\frac{V_{s, t}^{i}}{L_{s, t}^{i}}
$$

where $V_{s, t}^{i}$ is the value added of sector $s$ in country $i$ at time $t$ in constant prices. Notice, that since the above does not involve sectoral oil consumption, the sequences of labor 
productivities for each country $i$ and for each sector $s$, is known. Denote these sequences (normalized by Chinese GDP/worker in 2003) as $\left\{\bar{D}_{s, t}^{i}\right\}_{t=1970}^{2003}$.

Returning to the model, suppose that all parameters where known, and in particular suppose we had guessed a sequence of TFP parameters, $\left\{B_{s, t}^{i}\right\}_{t}$. Solving the model, we could calculate the implied labor productivity (in the model) as $D_{s, t}^{i}$ :

$$
D_{s, t}^{i}=D_{s, t}^{i}\left(B_{s, t}^{i}\right) \equiv \frac{p_{s, 0}^{i} B_{s, t}^{i}\left(\eta_{s} O_{s, t}^{i \xi_{s}}+\left(1-\eta_{s}\right) L_{s, t}^{i \xi_{s}}\right)^{\frac{1}{\xi_{s}}}-p_{0}^{O} O_{s, t}^{i}}{L_{s, t}^{i}}
$$

where the term in the numerator is the value added of a sector $s$ in country $i$ at time $t$ in period 0 prices (notice that this is just the gross output of sector $s$ less intermediate inputs - the oil used in the sector). The objective is thus to choose TFP levels, $B_{s, t}^{i}$, so that the model's implied labor productivity, matches observed labor productivity:

$$
D_{s, t}^{i}\left(B_{s, t}^{i}\right)=\bar{D}_{s, t}^{i}
$$

The above, is simply an extra equation, that must be solved for countries $i=C, D$ and sectors $s=A, I, S$ at every point in time $t$, together with the first order conditions for the extra unknown, $B_{s, t}^{i}$. Calculating the sequences of TFP in this way, I can find the annualized growth rate of the productivity, for all countries and for all sectors.

\subsubsection{Oil Consumption Calibration}

In this section, I estimate oil consumption by sector in China/India and the OECD in 1970. In order to do this (and for lack of sectoral oil consumption data in China/India and the OECD), I use the regression presented in equation 1.2 and Table 1.2 . These regressions describe what fraction of a sector's value added is devoted to oil at any point in the structural transformation and they are robust over time. According to these regressions, countries that employ $80 \%$ of their work force in agriculture - approximately the share employed by China/India in 1970 - spend 1\% of their agriculture value-added, $8 \%$ of their industry value-added and $7 \%$ of their service value added on oil. Since I have data on the value-added of Chinese/Indian agriculture, industry and services in 1970, this allows me to estimate the total value of oil used by each sector in 1970 $p_{O, 1970} O_{s, 1970}^{C}$. This allows me to calculate what fraction of total oil consumption in China/India was consumed by which sector, $\frac{p_{O, 1970} O_{s, 1970}^{C}}{\sum_{s} p_{O, 1970} O_{s, 1970}^{C}}=\frac{O_{s, 1970}^{C}}{\sum_{s} O_{s, 1970}^{C}}$. Given data 
on a country's total oil consumption, I can then estimate the quantity of oil consumed by each sector in each country and hence its share in total world oil consumption

Since I model the entire world as only the OECD and China/India, I need to make an assumption on how the oil that is not consumed by either the OECD (as defined in the text) or China/India in the data, is allocated across countries $C$ and $D$ in the model. In the data, China/India and the OECD (as defined in the text) consumed only $68 \%$ of the world's total oil consumption in 1970. Furthermore, this number did not stay constant over time, but fell to $60 \%$ by $2003 \mathrm{BP}$. This implies that I cannot assume that the growth rate of oil consumption in China/India and the OECD is the same as the growth rate of world oil output without adjusting the data. Consequently, I divide world oil consumption in the data into two groups: 1) The OECD and the Former Soviet Union 35 and 2) China/India and other emerging economies ${ }^{36}$. I match the oil consumed by the first group in the data to $D^{\prime} s$ oil consumption in the model and the oil consumption by the second group in the data to $C$ 's oil consumption in the model. This adjustment ensures that total oil consumption of $C$ and $D$ in the model grows at the same rate as world oil consumption in the data (by construction).

\subsubsection{Estimating Sectoral Oil-Labor Elasticities}

In this section, I estimate equation (1.14) using cross-sectional 1995 data for OECD countries, Brazil, Russia, India, China, Indonesia and South Africa. The sectoral oil consumption data is obtained from the Input-Output tables constructed by the OECD (2006). In my model, wages correspond to value added per capita. This data is taken from UN (2008). Finally, 1995 oil prices are taken from BP (2008). Taking the log of equation (1.14), I obtain:

$$
\log \left(\frac{O_{s, t}^{i}}{L_{s, t}^{i}}\right)=\sigma_{s} \log \left(\frac{\eta_{s}}{1-\eta_{s}}\right)+\sigma_{s} \log \left(\frac{w_{t}^{i}}{p_{t}^{O}}\right),
$$

\footnotetext{
35 For the purposes of dividing world oil output, the OECD consists of Australia, Austria, Belgium, Canada, Czech Republic, Denmark, Finland, France, Germany, Greece, Hungary, Iceland, Republic of Ireland, Italy, Japan, Luxembourg, Mexico, Netherlands, Norway, New Zealand, Poland, Portugal, Slovakia, South Korea, Spain, Sweden, Switzerland, Turkey, United Kingdom and the USA. The Former Soviet Union consists of: Armenia, Azerbaijan, Belarus, Estonia, Georgia, Kazakhstan, Kyrgyzstan, Latvia, Lithuania, Moldova, Russian Federation, Tajikistan, Turkmenistan, Ukraine and Uzbekistan.

36 These are all the other countries that are not in any of the other groups.
} 


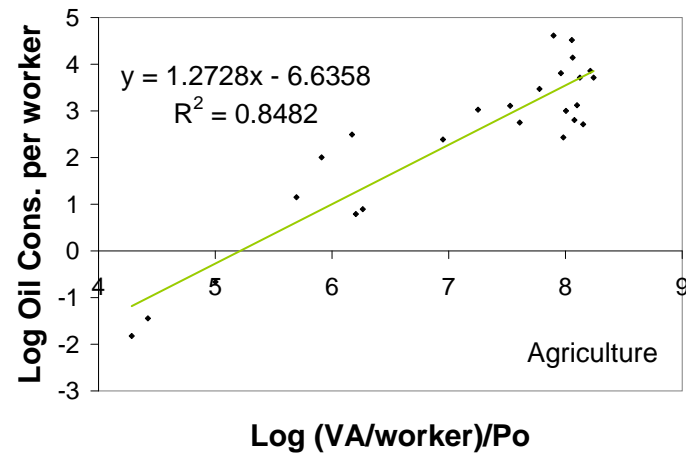

(a) Agriculture

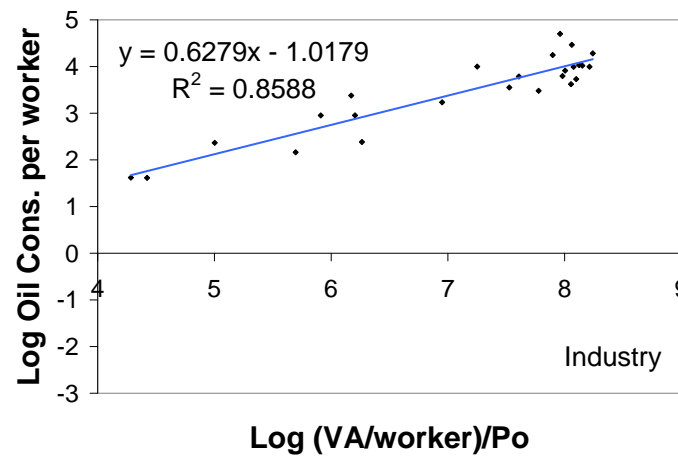

(b) Industry

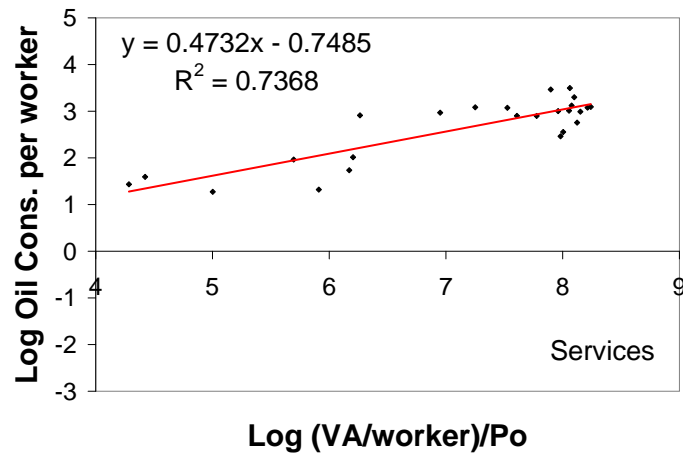

(c) Services

Figure 1.15: Regression Results

where $\sigma_{s}=\frac{1}{1-\xi_{s}}$. I estimate this equation using OLS and the results are shown in Figure 1.15. The slope parameter of each regression is the elasticity of substitution between oil and labor in a particular sector. 


\section{Bibliography}

E. Berndt and D. Wood. Technology, prices and the derived demand for energy. The Review of Economics and Statistics, 57:259-268, 1975.

BP. BP Statistical Review of World Energy June 2008, 2008. URL http://www.bp. com/statisticalreview.

Francisco J. Buera and Joseph P. Kaboski. Scale and the origins of structural change. No WP-08-06, Working Paper Series, Federal Reserve Bank of Chicago, 2008.

Colin J. Campbell and Jean H. Laherrre. The end of cheap oil. Scientific American, 278:3:78-84, 1998.

J.M. Daragay. Are price and income elasticities of demand constant? Oxford Institute for Energy Studies, 1992.

P. Dasgupta and G. Heal. The optimal depletion of exhaustible resources. The Review of Economic Studies, 41, 1974.

M. Duarte and D. Restuccia. The role of the structural transformation in aggregate productivity. Manuscrpit, 2007.

C. Echevarria. Changes in sectoral composition associated with economic growth. International Economic Review, 38, 1997.

EIA. EIAData.

Thomas Gold. The deep hot biosphere. Proceedings of the National Academy of Sciences, 13, 1992. 
L. C. Gray. Rent under the assumption of exhaustibility. Quarterly Journal of Economics, 28:466-489, 1914.

J. Griffin and P. Gregory. An intercountry translog model of energy substitution responses. The American Economic Review, 66:845-857, 1976.

H. Hotelling. The economics of exhaustible resources. Journal of Political Economy, 39:137-175, 1931.

ILO. Economically active population 1950-2010: Ilo database on estimates and projections of the economically active population (5th edition). 2003. URL http: //laborsta.ilo.org.

C. Kemfert. Estimated substitution elasticities of a nested ces production function approach for germany. Energy Economics, 20:249-264, 1998.

C. Kemfert and H. Welsch. Energy-capital-labor substitution and the economic effects of co2 abatement: Evidence for germany. Journal of Policy Modeling, 22:641-660, 2000 .

P. Kongsamut, S. Rebelo, and D. Xie. Beyond balanced growth. The Review of Economic Studies, 68, 2001.

Henrike Koschel. Substitution elasticities between capital, labour, material, electricity and fossil fuels in german producing and service sectors. ZEW Discussion Paper No. 00-31, 2000. URL AvailableatSSRN : http://ssrn. com/abstract=461521.

A Maddison. Phases of Capitalist Development. Oxford University Press, Oxford, 1982.

NBSC. National bureau of statistics of china, state council of the people's republic of china, 2006. URL http://www.stats.gov.cn/english/statisticaldata/ yearlydata/.

L. Ngai and C. Pissarides. Structural change in a multi-sector model of growth. The American Economic Review, 97, 2007.

OECD. OECD I-O Database - Industry Classification and Concordance with ISIC Rev 3, 2006 Edition. OECD, 2006. 
G. Proskurowski, M. Lilley, J. Seewald, G. Frueh-Green, E. Olson, J. Lupton, S. Sylva, and D. Kelley. Abiogenic hydrocarbon production at lost city hydrothermal field. Science, 319:604-606, 2008.

R. Rogerson. Structural transformation and the deterioration of european labor market. NBER Working Paper No. 12889, 2007.

B. Shankar, J. Piesse, and C. Thirtle. Energy substitutability in transition agriculture: estimates and implications for hungary. Agricultural Economics, 29:181-193, 2003.

R. Solow. Intergenerational equity and exhaustible resources. The Review of Economic Studies, 41, 1974.

J. Stiglitz. Growth with exhaustible natural resources: Efficient and optimal growth paths. The Review of Economic Studies, 41, 1974.

Marcel P. Timmer and Gaaitzen J. de Vries. A cross-country database for sectoral employment and productivity in asia and latin america, 1950-2005. Groningen Growth and Development Centre Research Memorandum GD-98, 2007.

UN. National Accounts Statistics database, 2008.

WDI. World development indicators, 2007. 